\title{
Bond strength between corroded steel and recycled aggregate concrete incorporating nano silica
}

\author{
Authors: Musab Alhawat*, Ashraf Ashour \\ Faculty of Engineering and Informatics, University of Bradford
}

\section{Abstract}

Limited information related to the application of nano silica in recycled aggregate concretes has been available in the literature. However, investigations on the effect of nano silica on the bond performance of reinforcement embedment length in recycled aggregate concrete have not been conducted yet. Therefore, the present study aimed at investigating the bond strength for recycled aggregate concretes incorporating nano silica under different levels of corrosive environments. The experimental work consisted of testing 180 pull-out specimens prepared from different mixtures. The main parameters studied were the amount of recycled aggregate (i.e. $0 \%, 25 \%, 50 \%$ and $100 \%$ ), nano silica (1.5\% and $3 \%$ ), embedment length (5 and 13Ø) as well as_reinforcement_diameter (12 and 20mm). Different levels of corrosion were electrochemically induced by applying impressed voltage technique for 2, 5, 10 and 15 days. Finally, the experimental results were compared with the existing models.

Experimental results showed that the bond performance between un-corroded steel and RCA concrete slightly reduced, while a significant degradation was observed after being exposed to corrosive conditions, in comparison to normal concrete. On the other hand, the use of a small quantity of NS (1.5\%) showed between 8 and $21 \%$ bond enhancement with both normal and RCA concretes under normal conditions. However, much better influence was observed with the increase of corrosion periods, reflecting the improvement in corrosion resistance. NS particles showed a more effective role with RCA concretes rather than conventional concretes in terms of enhancing bond and corrosion resistance. Therefore, it was superbly effective in recovering the poor performance in bond for RCA concretes. By doubling the content of NS (3\%), the bond resistance slightly enhanced for non-corroded samples, while its influence becomes more pronounced with increasing RCA content as well as exposure time to corrosion.

\section{Keywords}

Bond strength; Recycled aggregate concrete; nano silica; corrosion rate; pull-out test. 


\section{Introduction}

The use of recycled coarse aggregate $(\mathrm{RCA})$ produced from construction and demolition waste has received increasing interest owing to its potential environmental and economic benefits. The employment of recycled coarse aggregate $(R C A)$ in concrete can significantly contribute to minimizing the consumption of natural resource as well as landfill places [1]. Nevertheless, the use of RCA in concrete is still limited due to the inferiority in some of its properties, for example RCA is mainly composed of natural aggregate and adhered mortar, causing more porous to concrete, and creating a weak interfacial zone in concrete, and hence increasing their water absorption capacity compared to normal aggregate [2, 3]. This can lead to difficulties in controlling the fresh properties of concrete and consequently affecting the mechanical properties of hardened concrete, however, the main challenges are still how to effectively improve properties related to durability [4]. Therefore, the improvement of RCA properties has been one of the significant issues that attract researchers for extending the application of RCA in construction industry.

Bond strength of reinforced concrete is one of the fundamental properties which needs to be significantly evaluated to ensure the performance of steel reinforcing in structures, especially in severe environments. Bond between steel and concrete are heavily affected by different parameters such as concrete strength, embedment length, and bar diameter. Corrosion in steel reinforcement has been recently considered as another significant factor influencing the bond between steel and surrounding concrete [5]. Recent experimental investigations showed a slight decrease or comparable bond for RCA concrete, compared to conventional concrete [2, 6], However, much more degradation in bond strength was stated with RCA concretes after exposure to harsh corrosive environments [7].

In the literature, several techniques and approaches have been adopted for improving the performance of RCA in concrete. However, these techniques can be fundamentally classified in two routes, namely removing the weak surface of RCA, resulting from the existence of old cement mortar or strengthen and modifying the quality of adhered mortar. Removing the old mortar requires one of the following treatments, namely mechanical grinding [8], pre-soaking in acidic solutions [9] or ultrasonic cleaning [10]. On the other hand, improving the quality of adhered mortar can be achieved by coating the surface of RCA with different materials such as polymer emulsion, lime powder filler and pozzolanic materials such as silica fume and fly ash [11-14]. 
Recently, nano silica has been successfully applied in concrete field for improving concrete properties, owing to its beneficial contributions in filling nano and micro-voids available in the matrix, enhancing the pozzolanic reaction and acting as a nuclear for producing additional calcium-silicate-hydrate gels [15, 16]. All these features of nano silica are directly correlated to the ultra-small size and high specific surface area of its particles. Therefore, nano silica is seemingly a promising solution to enhance the inferior performance of RCA in concrete. In this context, limited information related to the application of nano-silica in RCA concrete has been available in the literature. More specifically, investigations on the bond strength between RCA concrete incorporating nano silica has not been conducted yet. Therefore, the main aim of the current study is to investigate the influence of nano silica on the corrosion resistance of RCA concretes as well as investigating the bond performance of RCA reinforced concretes under both normal and corrosive environmental conditions. For this purpose, hundred and eighty pull-out specimens with different amounts of recycled coarse aggregate (i.e. $0 \%, 25 \%, 50 \%$ and $100 \%$ ) and small contents of nano silica $(0 \%, 1.5 \%$ and $3 \%)$ were performed in this investigation. The influence of other parameters, namely embedment length, bar diameter and corrosion acceleration time were also studied. In addition, the obtained findings were compared to available equations for predicting the bond strength of un-corroded/corroded steel embedded in concrete.

\section{Experimental program}

\section{1. Materials}

A commercial Portland cement type CEM II was used in this study complying with EN 197-1:2011 [17]. Fine natural aggregate (NFA) was locally supplied with a maximum size $5 \mathrm{~mm}$, whilst two types of coarse aggregates were used; natural coarse aggregate (NCA) obtained from crushed limestone, and recycled coarse aggregate $(R C A)$ derived from construction and demolition waste $(C \& D)$ with a maximum size $20 \mathrm{~mm}$. The main characteristics of both coarse and fine aggregate are demonstrated in Table 1, whilst grading of the aggregates with BS 882-1992 limits [18] are plotted in Fig. 1.

Table 1. Physical characteristics of used aggregates.

\begin{tabular}{|c|c|c|c|}
\hline Aggregate Type & NFA & NCA & RCA \\
\hline Specific Gravity & 2.60 & 2.63 & 2.50 \\
\hline Water absorption (\%) & 2.10 & 1.06 & 4.4 \\
\hline Bulk density $\left(\mathrm{Kg} / \mathrm{m}^{3}\right)$ & 1580 & 1600 & 1360 \\
\hline Porosity (\%) & - & 40 & 46 \\
\hline
\end{tabular}

Note: $N F A=$ normal fine aggregate, $N C A=$ normal coarse aggregate, $R C A=$ recycled coarse aggregate. 


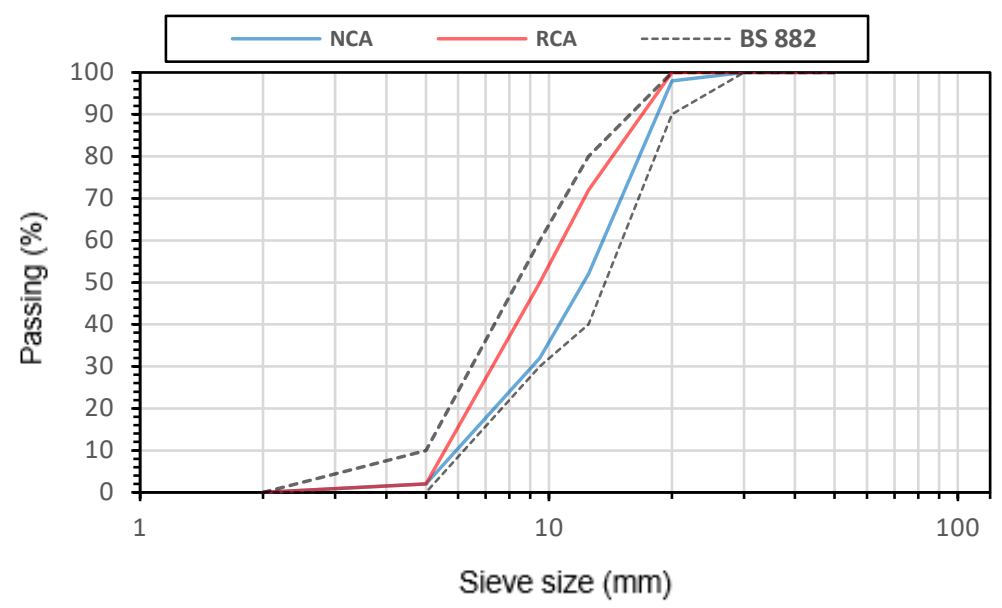

Fig. 1. Sieve analysis for RCA and NCA.

Nano silica in the colloidal form having a specific surface area of $250 \mathrm{~m}^{2} / \mathrm{g}$ and an average particle size of $15 \mathrm{~nm}$ was used as a replacement to cement in small dosages. The main properties of NS particles are described in Table 2, while its chemical composition compared to cement is presented in Table 3. It can be seen that NS made with high purity silica, which can be easily reacted with cement grains through the hydration process. Different amount of superplasticizers (SP) were added to various mixes as needed to keep similar workability of concrete at a slump level of $30-40 \mathrm{~mm}$, in accordance with BS EN 12,350 - 2:2009 EN [19]. The results obtained from the trail mixes showed that approximately $0.75 \%$ and $1.5 \%$ of SP were needed for mixtures prepared with $1.5 \%$ and $3 \%$ NS, respectively, to obtain almost similar slump value, since the workability significantly decreased with increasing the quantity of NS in the mixture. Two steel reinforcement bars were used in this study (12mm and $20 \mathrm{~mm})$, confirming the requirements of BS 4449, 2005 [20].

Table 2. The main properties of NS particles.

\begin{tabular}{|c|c|c|c|c|c|c|}
\hline Colour & Relative density & $\begin{array}{c}\text { Bulk density } \\
\left(\mathbf{k g} / \mathbf{m}^{\mathbf{3}}\right)\end{array}$ & $\begin{array}{c}\text { Particle size } \\
(\mathbf{n m})\end{array}$ & $\begin{array}{c}\text { Specific surface area } \\
\left(\mathbf{m}^{2} / \mathbf{g}\right)\end{array}$ & $\begin{array}{c}\text { pH } \\
\text { Solid content } \\
(\%)\end{array}$ \\
\hline translucent & 1.2 & 1200 & 15 & 250 & 6.8 & 30 \\
\hline
\end{tabular}

Table 3. The chemical components of cement and nano silica.

\begin{tabular}{|l|c|c|c|c|c|c|c|c|c|}
\hline Component & $\mathrm{SiO}_{2}$ & $\mathrm{CaO}$ & $\mathrm{Al}_{2} \mathrm{O}_{3}$ & $\mathrm{FeO}_{3}$ & $\mathrm{MgO}$ & $\mathrm{SO}_{3}$ & $\mathrm{Na}_{2} \mathrm{O}$ & $\mathrm{R}_{2} \mathrm{O}$ & L.O.I \\
\hline Cement & 20.00 & 63.00 & 5.5 & 0.5 & 1.0 & 3.2 & 0.37 & 0.12 & 2.00 \\
\hline $\mathrm{NS}$ & 99.99 & - & - & - & - & - & - & - & 0.01 \\
\hline
\end{tabular}

\section{2. Concrete mix design, casting and curing}

A total of twelve different mixtures containing NCA, RCA and NS were designed, as shown in Table 4, and all concrete mixes made with the same water to binder ratio of 0.4 . The first four groups were prepared with different replacement levels of recycled coarse aggregates (i.e. $0 \%, 25 \%, 50 \%$ and 
$100 \%)$. The remaining concrete groups were performed in the same way except for replacing small dosages of cement by nano silica (1.5\% and $3 \%$ ). Each mixture is composed of 15 specimens divided into three different series. It should be noted that the amount of water required for NCA and RCA aggregates to be in a saturated surface dry condition (SSD) was added to the mix by calculating the difference between water absorption and water content of aggregates. However, previous investigations [21], demonstrated that compensating only about $80-90 \%$ of extra water absorption of the recycled aggregates showed better performance of RCA concrete than $100 \%$ compensation of extra water absorption. It is important to note that even though the water absorption of recycled aggregates is almost four times higher than that of the natural aggregates, it is still relatively low compared with RCA used in previous studies [22, 23], which might have improved concrete results. After finishing the cast, the specimens were left $24 \mathrm{~h}$ at room temperature before they were demoulded. Then, all specimens were immediately covered by plastic sheets for 28 days until the day of test.

Table 4. Concrete mixture proportions $\left(\mathrm{Kg} / \mathrm{m}^{3}\right)$.

\begin{tabular}{|c|c|c|c|c|c|c|c|}
\hline Series & NCA & $\boldsymbol{R C A}$ & NFA & Cement & Water & NS & SP \\
\hline R0 & 1180 & - & 664 & 450 & 180 & - & - \\
\hline R25 & 885 & 255 & 664 & 450 & 180 & - & - \\
\hline R50 & 590 & 510 & 664 & 450 & 180 & - & - \\
\hline R100 & - & 1120 & 664 & 450 & 180 & - & - \\
\hline R0-NS1.5 & 1180 & - & 664 & 443.25 & 180 & 6.75 & 3.75 \\
\hline R25 NS1.5 & 885 & 255 & 664 & 443.25 & 180 & 6.75 & 3.75 \\
\hline R50- NS1.5 & 590 & 510 & 664 & 443.25 & 180 & 6.75 & 3.75 \\
\hline R100- NS1.5 & - & 1120 & 664 & 443.25 & 180 & 6.75 & 3.75 \\
\hline R0-NS3 & 1180 & - & 664 & 436.5 & 180 & 13.5 & 7.5 \\
\hline R25-NS3 & 885 & 255 & 664 & 436.5 & 180 & 13.5 & 7.5 \\
\hline R50-NS3 & 590 & 510 & 664 & 436.5 & 180 & 13.5 & 7.5 \\
\hline R100-NS3 & - & 1120 & 664 & 436.5 & 180 & 13.5 & 7.5 \\
\hline
\end{tabular}

Note: $N C A=$ normal coarse aggregate; $R C A=$ recycled coarse aggregate; $N F A=$ normal fine aggregate; $N S=$ nano silica; $S P=$ superplasticizers .

\section{3. Pull out test specimen details}

All pull out test specimens had dimensions of $(200 \times 200 \times 200 \mathrm{~mm})$ with a single rebar placed at the centre of each specimen, however, these specimens were made in three series with different parameters (i.e. bar diameter and embedment length). While the first and second series were performed with the same reinforcing bar diameter $(12 \mathrm{~mm})$ and having different embedment length, the third one was carried out with the same bonded area as that of the second series using reinforcing steel $20 \mathrm{~mm}$. The embedment length for the first and third series was chosen to be five times of reinforcement bar diameter, whereas it was selected 13 times of bar diameter for the second series to give the same bonded area as used in the third series $\left(6280 \mathrm{~mm}^{2}\right)$. The un-bonded part of bar located in the cube was 
coated by a PVC sleeve to prevent the contact with concrete. The lower part for all specimens was carefully isolated to prevent the steel from being exposed to corrosion. Details of test specimens are demonstrated in Fig. 2 and Table 5. To obtain various levels of corrosion, five specimens were exposed to different periods of corrosion in each series.

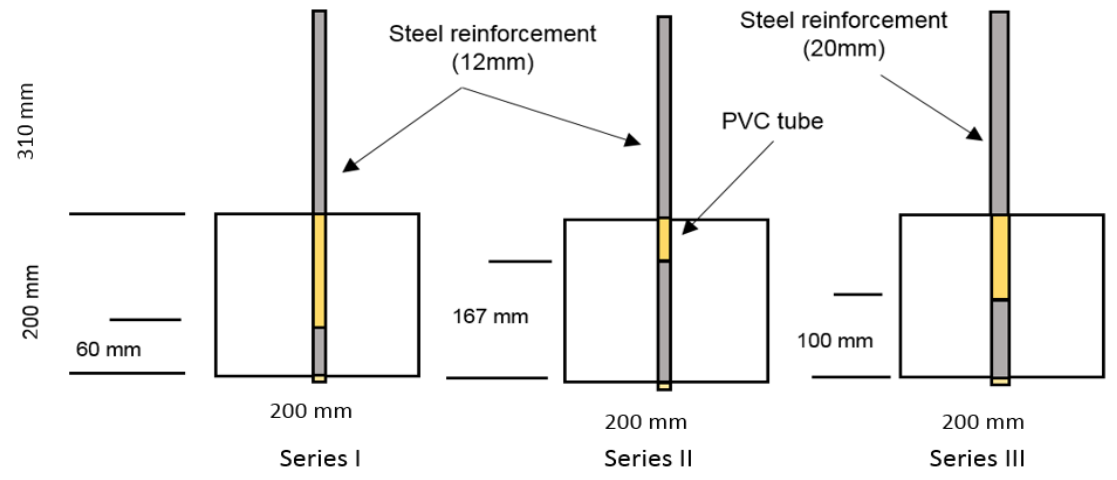

Fig. 2. Test specimen's configurations.

\section{4. Accelerated Corrosion Test Setup}

Because reinforcement corrosion is a slow process under natural conditions, and it would take a long time for steel reinforcement to be corroded, the impressed voltage technique was used for inducing corrosion. This has the advantage in saving time as well as allowing the corrosion rate to be controlled during time of test by adjusting the applied voltage $[24,25]$. The specimens were placed in plastic tanks containing $3.5 \%$ sodium chloride solution by weight of water to simulate the conditions found in marine environments. $\mathrm{NaCl}$ solution was filled up to about $90 \%$ of specimens' volume and current was applied from an external power supply to induce corrosion in reasonable time. A stainless bar was placed with each series to act as the cathode, and the specimens were connected in parallel with the DC power supply to be as the anode as shown in Fig. 3. In order to obtain different levels of corrosion, a constant voltage was applied using a DC power supply for all series, and the corresponding current depended upon the conductivity of concrete, and accelerated corrosion time was maintained for 2,5,10 and 15 days. 


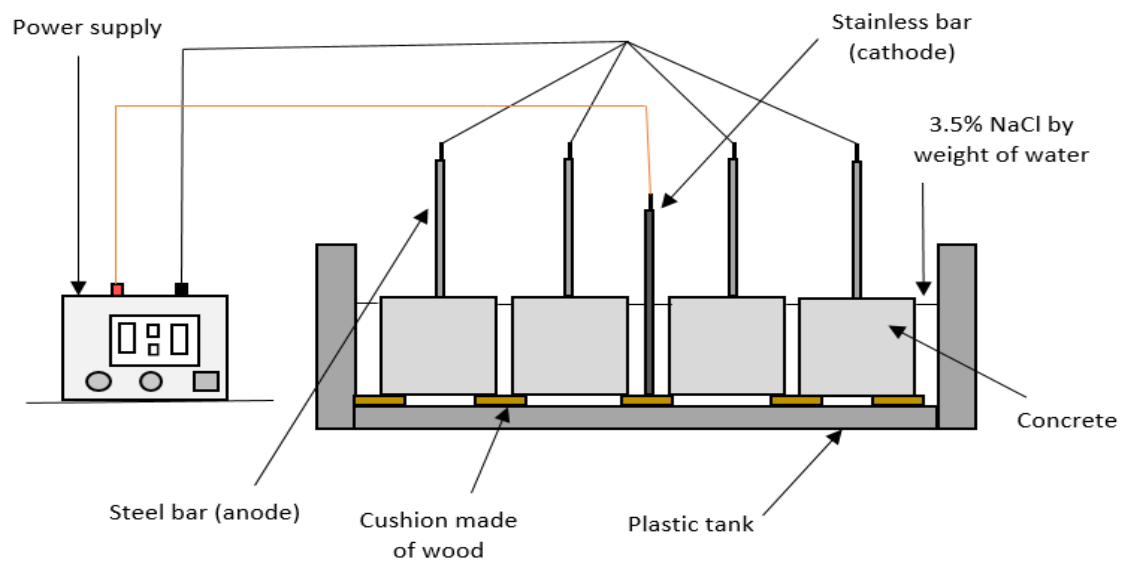

Fig.3. Corrosion acceleration technique.

Table 5. Description of tested specimens.

\begin{tabular}{|c|c|c|c|c|c|}
\hline Group & NS \% & RCA \% & $\varnothing(\mathrm{mm})$ & Id $(\mathrm{mm})$ & $\begin{array}{c}\text { Period of corrosion } \\
\text { (days) }\end{array}$ \\
\hline \multirow{3}{*}{ R0 } & \multirow{3}{*}{0} & \multirow{3}{*}{0} & 12 & 60 & $0,2,5,10,15$ \\
\hline & & & 12 & 167 & $0,2,5,10,15$ \\
\hline & & & 20 & 100 & $0,2,5,10,15$ \\
\hline \multirow{3}{*}{$\mathrm{R} 25$} & \multirow{3}{*}{0} & \multirow{3}{*}{25} & 12 & 60 & $0,2,5,10,15$ \\
\hline & & & 12 & 167 & $0,2,5,10,15$ \\
\hline & & & 20 & 100 & $0,2,5,10,15$ \\
\hline \multirow{3}{*}{$\mathrm{R} 50$} & \multirow{3}{*}{0} & \multirow{3}{*}{50} & 12 & 60 & $0,2,5,10,15$ \\
\hline & & & 12 & 167 & $0,2,5,10,15$ \\
\hline & & & 20 & 100 & $0,2,5,10,15$ \\
\hline \multirow{3}{*}{ R100 } & \multirow{3}{*}{0} & \multirow{3}{*}{100} & 12 & 60 & $0,2,5,10,15$ \\
\hline & & & 12 & 167 & $0,2,5,10,15$ \\
\hline & & & 20 & 100 & $0,2,5,10,15$ \\
\hline \multirow{3}{*}{ R0-NS 1.5} & \multirow{3}{*}{1.5} & \multirow{3}{*}{0} & 12 & 60 & $0,2,5,10,15$ \\
\hline & & & 12 & 167 & $0,2,5,10,15$ \\
\hline & & & 20 & 100 & $0,2,5,10,15$ \\
\hline \multirow{3}{*}{ R25-NS 1.5} & \multirow{3}{*}{1.5} & \multirow{3}{*}{25} & 12 & 60 & $0,2,5,10,15$ \\
\hline & & & 12 & 167 & $0,2,5,10,15$ \\
\hline & & & 20 & 100 & $0,2,5,10,15$ \\
\hline \multirow{3}{*}{ R50-NS 1.5} & \multirow{3}{*}{1.5} & \multirow{3}{*}{50} & 12 & 60 & $0,2,5,10,15$ \\
\hline & & & 12 & 167 & $0,2,5,10,15$ \\
\hline & & & 20 & 100 & $0,2,5,10,15$ \\
\hline \multirow{3}{*}{ R100-NS 1.5} & \multirow{3}{*}{1.5} & \multirow{3}{*}{100} & 12 & 60 & $0,2,5,10,15$ \\
\hline & & & 12 & 167 & $0,2,5,10,15$ \\
\hline & & & 20 & 100 & $0,2,5,10,15$ \\
\hline \multirow{3}{*}{ R0-NS3 } & \multirow{3}{*}{3} & \multirow{3}{*}{0} & 12 & 60 & $0,2,5,10,15$ \\
\hline & & & 12 & 167 & $0,2,5,10,15$ \\
\hline & & & 20 & 100 & $0,2,5,10,15$ \\
\hline \multirow{3}{*}{ R25-NS3 } & & & 12 & 60 & $0,2,5,10,15$ \\
\hline & 3 & 25 & 12 & 167 & $0,2,5,10,15$ \\
\hline & & & 20 & 100 & $0,2,5,10,15$ \\
\hline & & & 12 & 60 & $0,2,5,10,15$ \\
\hline R50-NS3 & 3 & 50 & 12 & 167 & $0,2,5,10,15$ \\
\hline & & & 20 & 100 & $0,2,5,10,15$ \\
\hline & & & 12 & 60 & $0,2,5,10,15$ \\
\hline R100-NS3 & 3 & 100 & 12 & 167 & $0,2,5,10,15$ \\
\hline & & & 20 & 100 & $0,2,5,10,15$ \\
\hline
\end{tabular}




\section{5. Test procedures}

\section{5.1. Compressive strength}

The compressive strengths of each mixture were measured at 7,28 and 90 days of curing in accordance with BS EN12390-3, 2009 [26] using $(100 \mathrm{~mm} \times 100 \mathrm{~mm} \times 100 \mathrm{~mm})$ cubes.

\section{5. 2. Pull-out test}

Pull-out tests were performed based on RILEM specifications [27] using a Denison machine of $500 \mathrm{KN}$ load capacity as illustrated in Fig. 4. Pull-out specimens were set between two steel plates, and a rubber sheet was positioned above specimen' surface to ascertain a uniform distribution of the applied load. Three high precision linear variable differential transducers (LVDTs) were connected to a data logger to accurately measure the slip occurred against the load. The applied load and slip between the rebar and concrete was simultaneously recorded at a rate of $0.01 \mathrm{~mm} / \mathrm{min}$ up to failure. The bonding stress was assumed to be uniformly distributed along the bonded length. Accordingly, the bond stress was calculated by Eq. 1 .

$$
\tau_{u}=P / \pi D L
$$

where $\tau_{u}$ is the bond strength, $P$ is the applied load, $D$ is the bar diameter and $L$ is the embedment length.

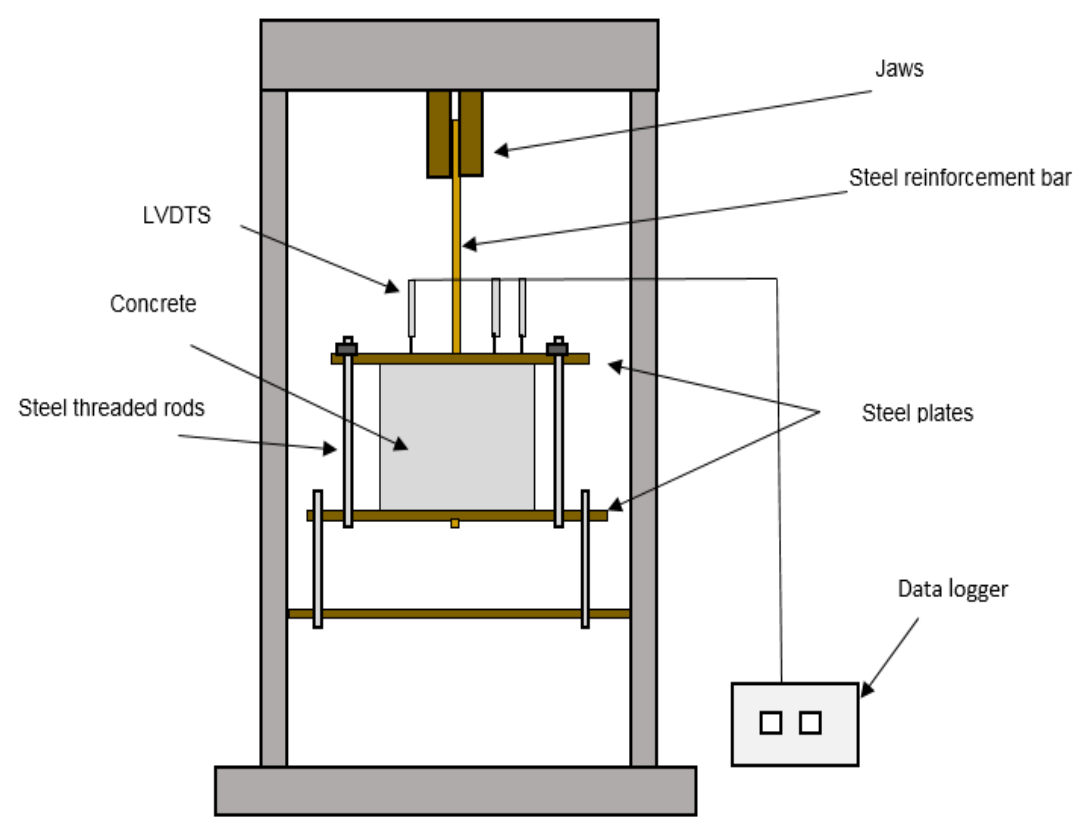

Fig. 4. Setup of the pull-out test.

\section{5. 3. Mass loss measurement}

The rebar was taken out from concrete and immersed in a hydrochloric acid solution, and subsequently cleaned by water and a wire brush as it is recommended by ASTM G-1 [28] to remove any rust on the 
surface of the bar. The mass of rebar was recorded after removing the rust and compared to the initial mass of the bar before corrosion. The corrosion level was calculated by Eq. 2:

$$
\eta=\frac{\left(G_{1}-G_{2}\right)}{g_{0} * l}
$$

where $\eta$ is the corrosion level of reinforcing steel, $G_{1}$ is the mass of steel bar before the reinforcement corroded, $G_{2}$ is the mass of steel after corrosion and $g_{0}$ is the mass per unit length of reinforcing bar, and $l$ is the bonded length.

\section{Results and discussions}

\subsection{Mechanical properties}

The compressive strengths of NCA and RCA concretes made with and without nano silica at the ages of 7, 28 and 90 days are exhibited in Fig. 5. From the presented results, it can be seen that the compressive strength tends to decrease as the replacement content of RCA in the mixture increases at all test ages. The use of $50 \%$ and $100 \%$ RCA resulted in $8.5 \%$ and $15 \%$ reduction of compressive strength at 28 days, respectively, in comparison with normal concrete. It is documented that the strength of concrete is mainly dependent on aggregates' strength, cement and the weak interfacial transition ITZ between aggregate and cement mortar. The reduction in strength of RCA concrete is commonly linked to the ITZ located between the old and new cement, resulting from the presence of attached old mortar on aggregates' surface. However, as the time of curing reached 90 days, the development of strength for 50 and $100 \mathrm{RCA}$ concretes were slightly higher than that found in conventional concrete reporting $9.5 \%$ and $11.5 \%$ enhancement, respectively, whilst the normal concrete just enhanced $8 \%$.

By incorporating $1.5 \% \mathrm{NS}$ in mixtures, it can be clearly seen that the compressive strength for both normal and recycled aggregate concretes greatly enhanced, especially at an early age (7days) achieving $30 \%$ and $43 \%$, respectively, of their respective compressive strengths without NS, owing to the extremely high specific surface area of nano silica, which in turn accelerates the hydration rate and facilitate the reaction with calcium hydroid $\mathrm{Ca}(\mathrm{OH})_{2}$, producing an additional calcium silicate hydrate. However, the effect of NS became less for both NCA and RCA concretes in terms of strength development as time of curing increases, reporting just $17 \%$ and $18.3 \%$ enhancement, respectively at 90 days compared to those made without NS, agreeing with the results obtained by [29]. Moreover, the 
addition of $1.5 \%$ nano silica to fully RCA concretes was sufficient and even better than the conventional concrete in terms of compressive strength at all age tested.

Regarding the effect of NS content, it can be seen that by doubling the replacement content of NS to be $3 \%$, the strength of concrete continually promoted, making $29.5 \%$ and $37.5 \%$ enhancement at 28 days for NCA and RCA concrete, respectively, which are between $7-13 \%$ higher than that reported with $1.5 \%$ NS. This slight improvement might have occurred as a result of agglomeration state, preventing some NS particles from reacting with cement particles. The results also indicated that the substitution $25 \%$ of NCA by RCA showed almost the same trend with the obtained in normal concrete at all test ages, regardless of the replacement dosage of nano silica, which in agreement with previous research [30]. With respect to strength gain, the findings showed that the $100 \%$ RCA concrete incorporating NS achieved higher strength gain ratio, in comparison with conventional concrete at all curing ages. This increased gain ratio is mainly attributed to the higher capillary spaces and larger pores available in the microstructure of RCA concrete. Therefore, NS particles can easily fill up these spaces, in addition to the ability of such particles in reacting with the large amount of $\mathrm{Ca}(\mathrm{OH})_{2}$ found in RCA concrete, producing more $\mathrm{C}-\mathrm{S}-\mathrm{H}$ gel, which is similar to that reported in recent investigations done by some [29]. 


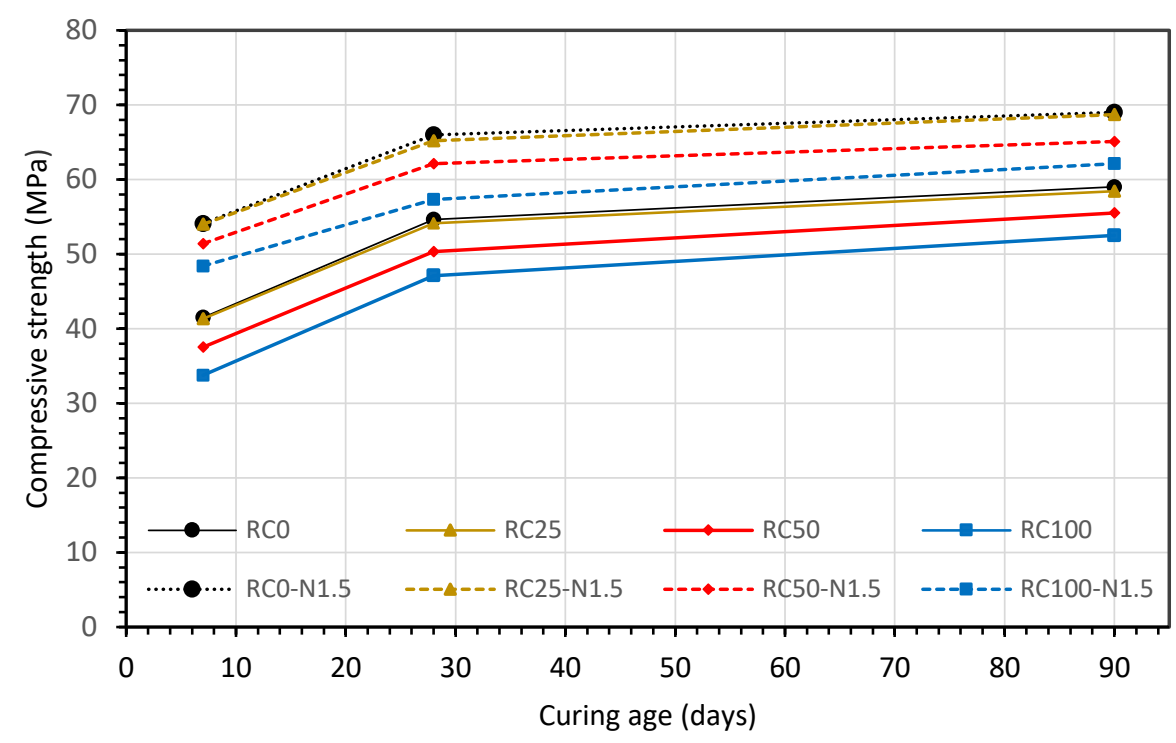

(a)

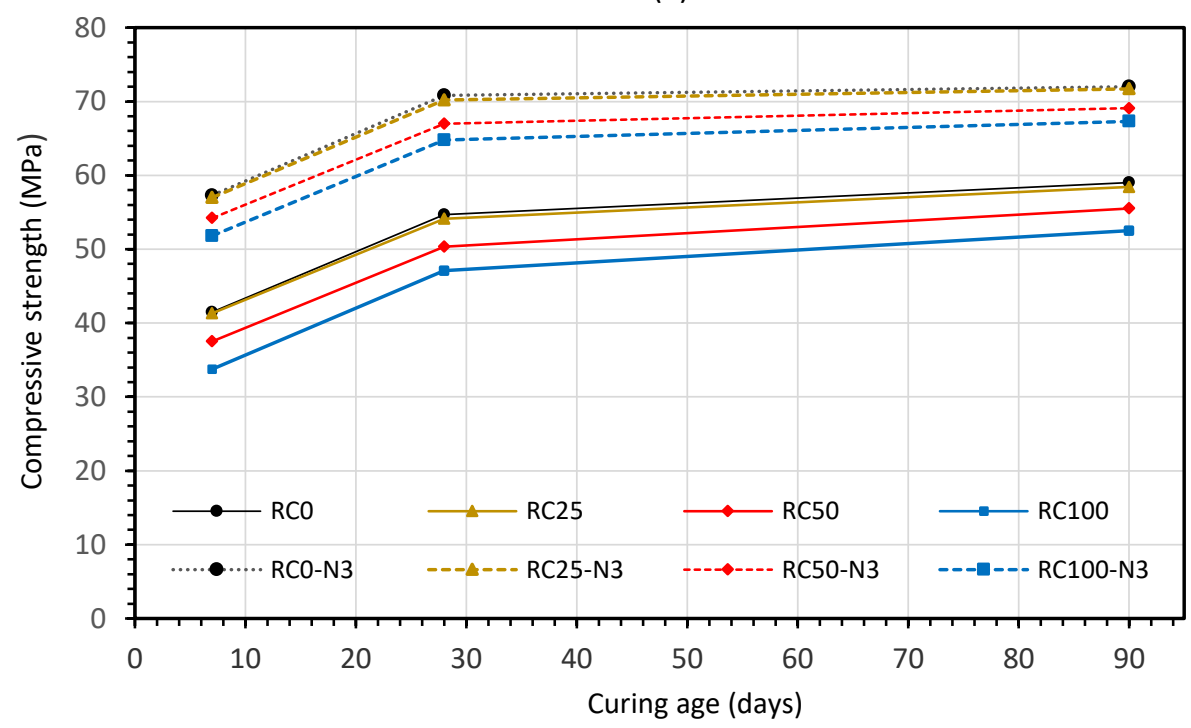

(b)

Fig. 5. Compressive strength of concrete mixes made with: (a). $1.5 \%$ NS and (b). $3 \%$ NS.

\section{2. Influence of nano silica on corrosion resistance}

The corrosion rates resulted from applying impressed voltage technique for each exposure period (2, 5, 10 and 15 days) are presented together in Fig. 5. A wide range of corrosion rate in terms of mass loss was obtained during the current investigation ranging between $0.7 \%$ up to about $20 \%$. As can be seen from Fig. 6, higher mass loss was reported with specimens having larger embedment length ( $\varnothing$ $12 \mathrm{~mm}, l_{d}=167 \mathrm{~mm}$ ), since some longitudinal cracks were spotted with such specimens, allowing chloride ions to readily reach steel surface. From the presented results, it can be recognised that the corrosion rate has significantly raised for the three different types of specimens when NCA was 
substituted by $50 \%$ and $100 \%$ RCA, whilst the replacement of quarter quantity showed comparable results. For instance, the average mass loss after two days for specimens made with $100 \% \mathrm{RCA}$ specimens having $167 \mathrm{~mm}$ bonded length was about $20 \%$ higher than those free of RCA. This influence developed over exposure time to be about $23 \%$ and $37 \%$ higher corrosion, respectively, compared to reference concrete, and became more apparent by reaching 15 days, reporting more than $20 \%$ weight loss, which approximately $40 \%$ higher compared to normal concrete. This is fundamentally ascribed to the high water absorption and permeability of RCA, which are directly related to the presence of old paste mortar on aggregate' surface. The higher corrosion rates might be also linked to the presence of contaminants in RCA (e.g. sulfate, chloride and carbonate), which facilitate the de-passivation of protective film around steel reinforcement [31]. Nevertheless, the addition of $1.5 \%$ NS to mixtures considerably enhanced the resistance of specimens against corrosion for both normal and RCA concretes. For example, the average corrosion rate for R0-NS1.5 is reduced by about $31 \%, 36 \%, 45 \%$ and $48 \%$ at 2, 5, 10 and 15 days, respectively owing to the pore filling ability of nano-silica, as it fills the pores up to nano size, and thereby making concrete less permeable. This improvement in corrosion resistance was more obvious with the increment of RCA content, reporting lower corrosion rates of $40 \%, 42 \%, 45 \%$ and $52 \%$ for $100 \% \mathrm{RCA}$ at the same periods. This might be explained by the higher capillary spaces and larger pores available in the microstructure of RCA concretes. It is also observed that the incorporation of $1.5 \%$ NS with 100RCA concrete reduced the growth of corrosion and showed a slightly better resistance at all ages, in comparison with control specimens made without NS. By doubling the quantity of NS to $3 \%$, lower corrosion products were accumulated around steel reinforcements for all mixes; however, the corrosion rate reduced by just $5-25 \%$, in comparison with those containing $1.5 \%$ NS. 

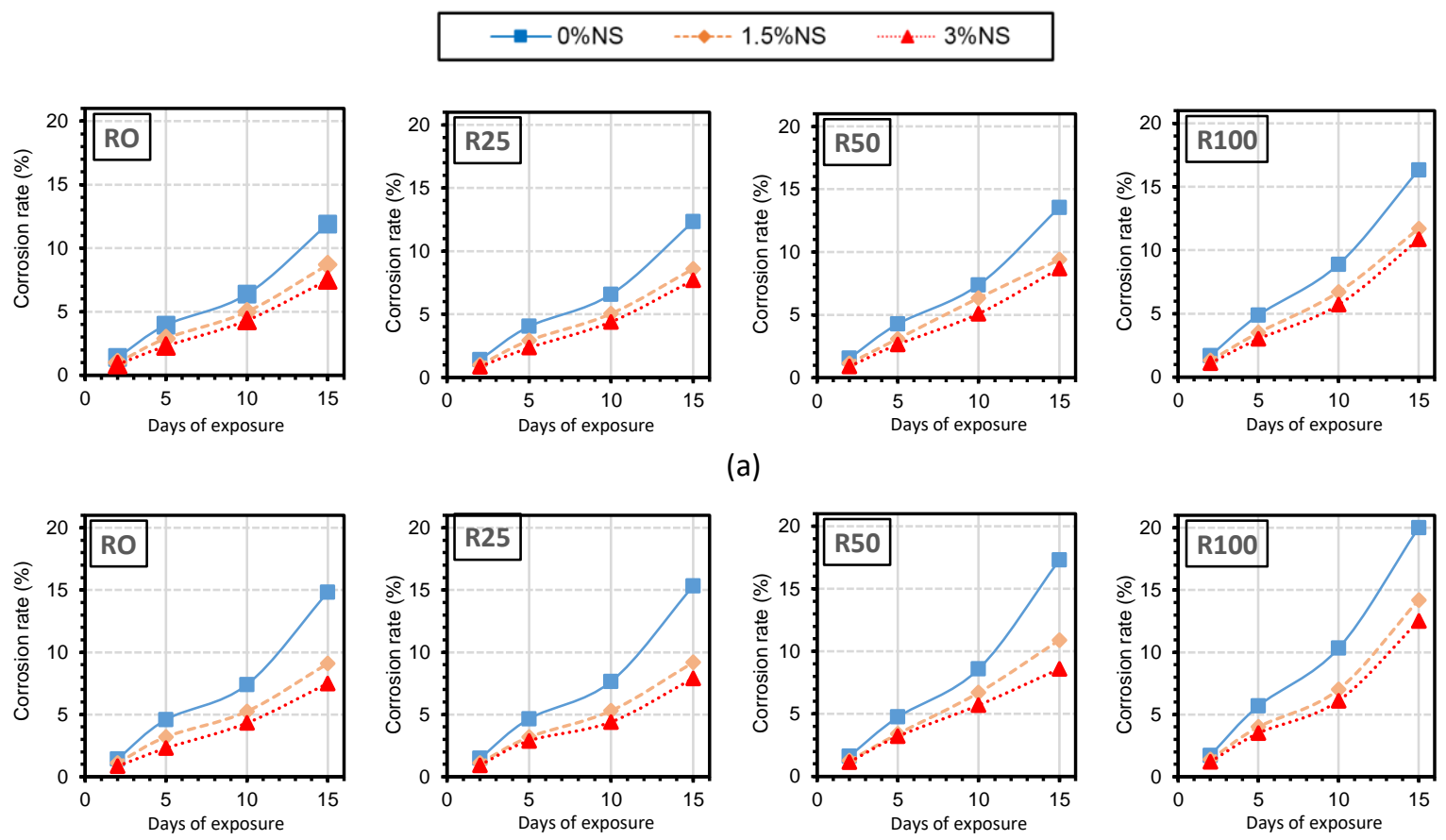

(a)
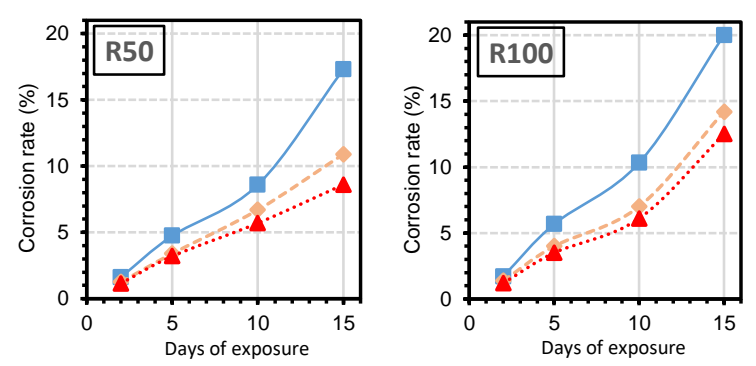

(b)
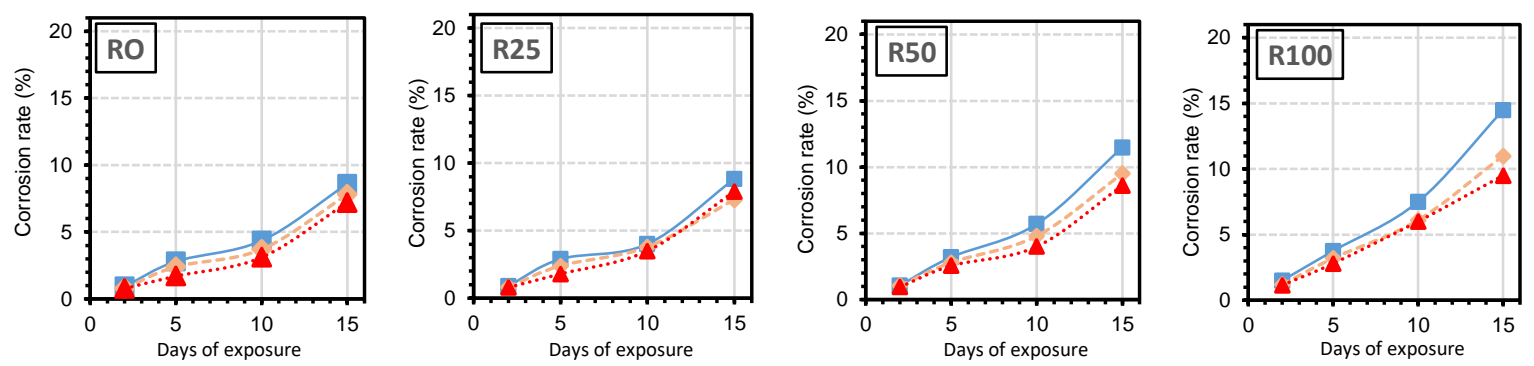

(c)

Fig. 6. Variation of corrosion levels for specimens having; (a). $\varnothing 12 \mathrm{~mm}-\mathrm{l}_{d}=60 \mathrm{~mm}$; (b). $\varnothing 12 \mathrm{~mm}-\mathrm{I}_{d}=167 \mathrm{~mm}$; (c). $\varnothing$ $20 \mathrm{~mm}-\mathrm{l}_{\mathrm{d}}=100 \mathrm{~mm}$.

Fig. 7 shows the visual observations for the three types of specimens having $100 \%$ RCA made with and without NS. For those prepared without NS, it can be seen that the specimens were deeply corroded and brownish rust was noticed along the vicinity of steel embedment, whereas fluid corrosion oxides with an orange colour were spread over the internal concrete surface, nevertheless, these products became less pronounced when NS was added to concrete. It can also obviously noticed that nano silica contributed to improving concrete protection against the propagation of steel corrosion for the three types of specimens as concrete mixtures became less impermeable. Another observation from Fig. 7 is the higher corrosion products available with specimens having larger embedment length $(\varnothing 12 \mathrm{~mm}$, $I_{d}=167 \mathrm{~mm}$ ), since longitudinal cracks were spotted with such specimens, allowing chloride ions to readily reach steel surface, and hence corrosion process was accelerated and more electrons moved between cathodes and anodes sites. 

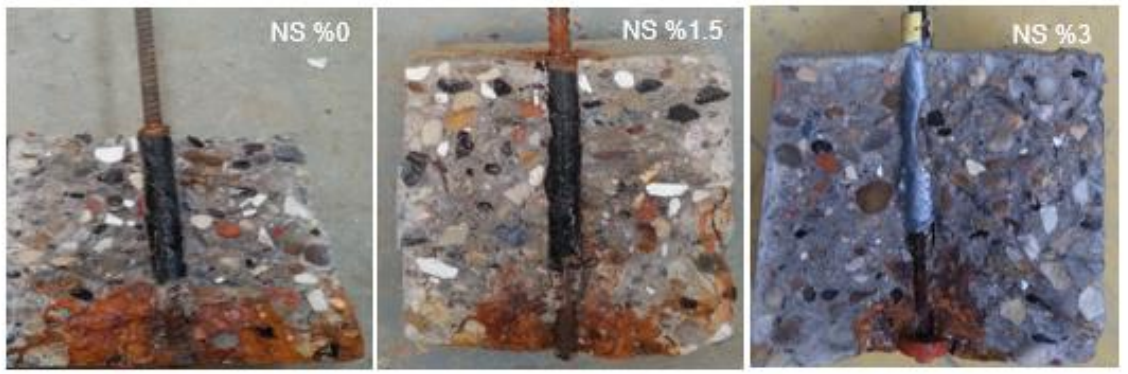

(a)
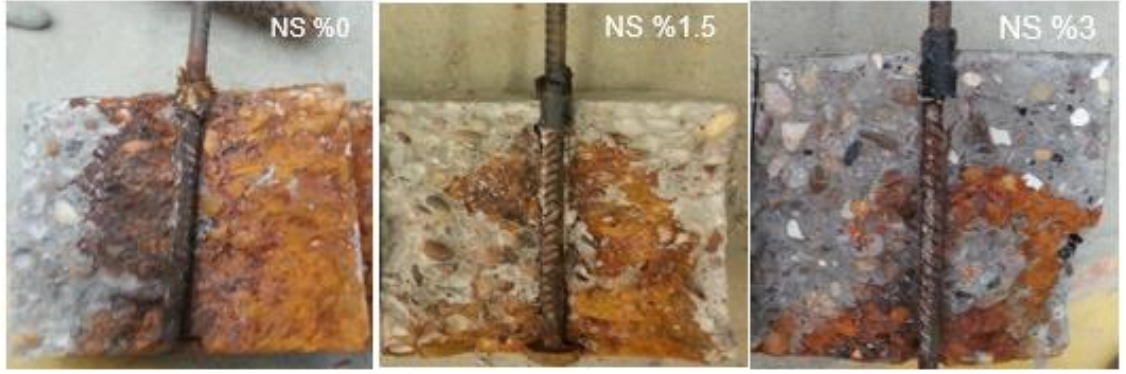

(b)
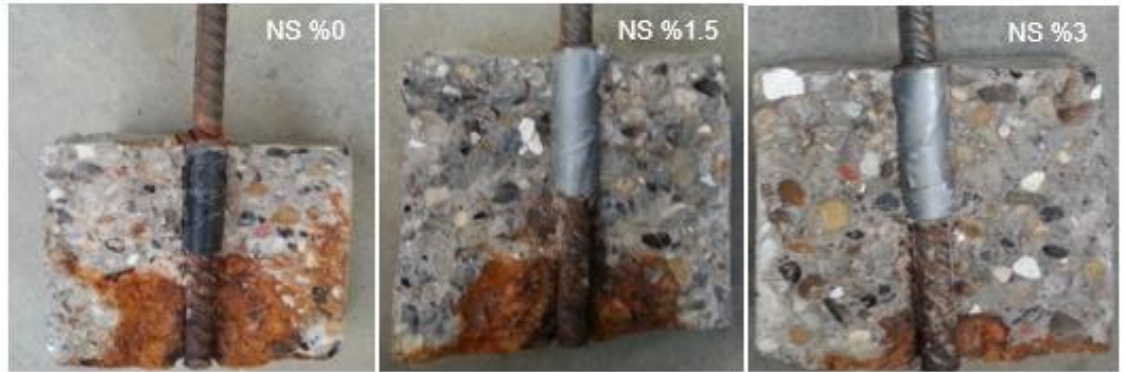

(c)

Fig. 7. Comparison of steel corrosion in RCA concretes incorporating NS for specimens having: (a). $\varnothing 12 \mathrm{~mm}-\mathrm{I}_{d}=$ $60 \mathrm{~mm}$; (b). $\varnothing 12 \mathrm{~mm}-\mathrm{l}_{\mathrm{d}}=167 \mathrm{~mm}$; (c). $\varnothing 20 \mathrm{~mm}-\mathrm{l}_{\mathrm{d}}=100 \mathrm{~mm}$.

\section{3. Bond strengths of reinforced concretes made with nano silica}

\section{3. 1. Bond stress- slip relationship}

Due to the large number of specimens tested in this work, only the bond stress-slip relationships for $100 \%$ RCA concrete made without and with $3 \%$ NS were selected to be presented in this section. Figs. 8-10 show the bond stress versus slip for the three types of specimens $\left(\varnothing 12 \mathrm{~mm}-\mathrm{I}_{d}=60 \mathrm{~mm}, \varnothing 12 \mathrm{~mm}\right.$ $I_{d}=167 \mathrm{~mm}$ and $\varnothing 20 \mathrm{~mm}-\mathrm{l}_{d}=100 \mathrm{~mm}$ ) before and after adding NS. As shown in Fig. 7, the bond stressslip curves can be divided into 3 stages, and possibly 4 stages in some cases. A marginal slip between steel and concrete occurred in the first stage, whilst the stress is rapidly increased up to reach the peak value. It should be noted that the bond stress of specimens containing NS (free and had a little corrosion) slightly increased accompanied by a rapid increase in slip displacement after reaching steel reinforcement to yielding, whilst this part was not observed with those made without NS. Thereafter, the 
bond stress began decreasing with a gradual increase in displacement, resulting from the occurrence of pull-out failure. In the last stage, the residual stress became almost constant when it reached about $30 \%$ of the stress peak. For specimens having $167 \mathrm{~mm}$ embedment length as shown in Fig. 8, slow development in bond stress was observed for those un-corroded/slightly corroded accompanied by a speed displacement after reaching about $10 \mathrm{MPa}$, resulting from yielding of steel, which continued until the peak point. Then, the bond stress suddenly dropped due to the occurrence of splitting failure for those free of NS, whilst unexpected failure occurred for specimens made with NS before reaching the peak due to the rupture occurred in reinforcement prior to bond failure. As shown in Fig. 9, all specimens made with $100 \mathrm{~mm}$ embedment length showed the same trend regardless of corrosion rate and NS content. This can be observed as the bond stress speedily increased with a slight increase in slip till reaching the peak, then a sudden drop in bond stress was observed.

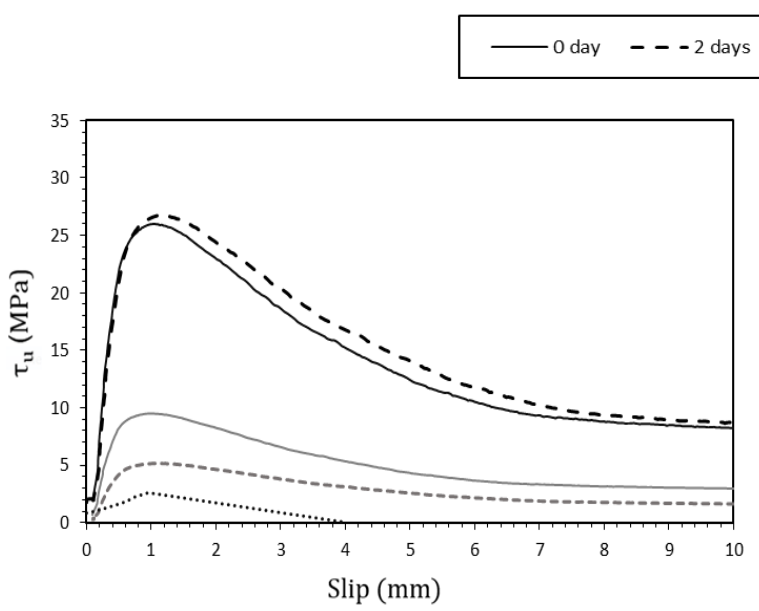

(a)

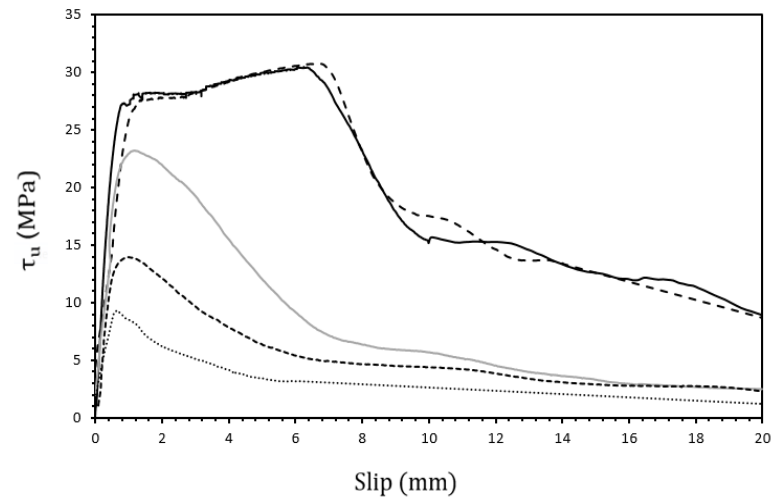

(b)

Fig. 8. Bond stress versus slip for specimens having $\varnothing 12 \mathrm{~mm}-\mathrm{l}_{d}=60 \mathrm{~mm}$ and (a). R100 and (b). R100-NS3.

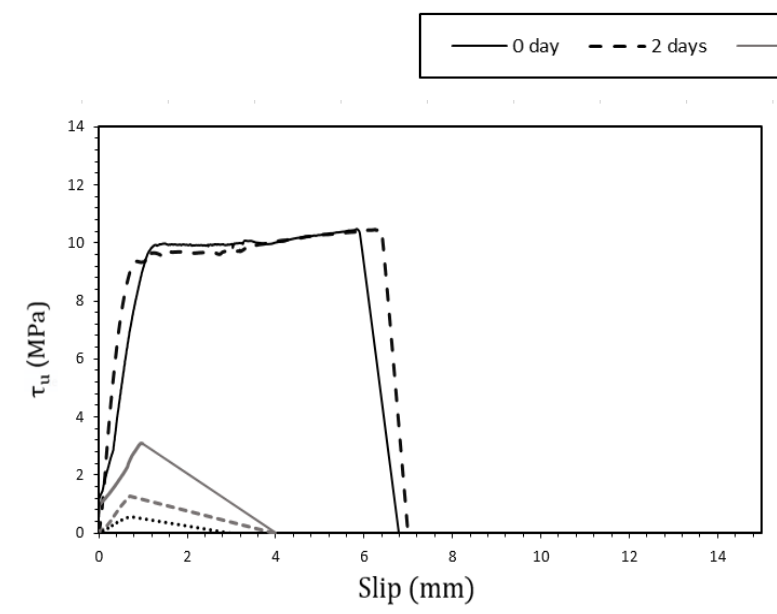

(a)

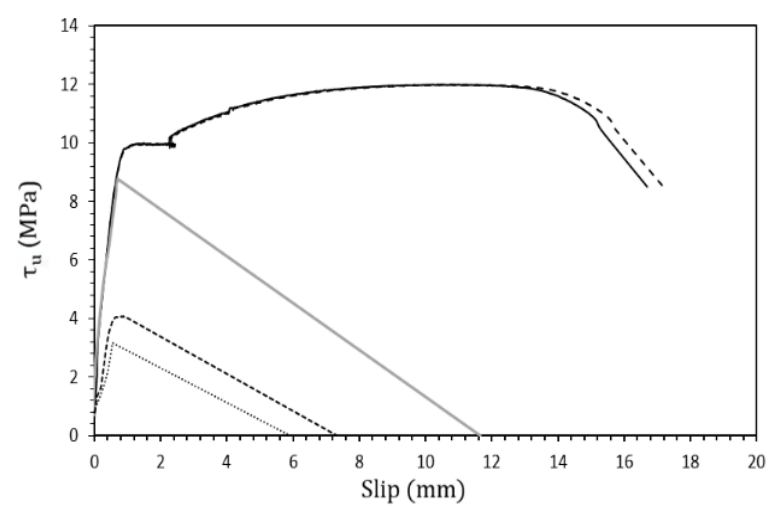

(b)

Fig. 9. Bond stress versus slip for specimens having $\varnothing 12 \mathrm{~mm}-\mathrm{l}_{\mathrm{d}}=167 \mathrm{~mm}$ and (a). R100 and (b). R100-NS3. 


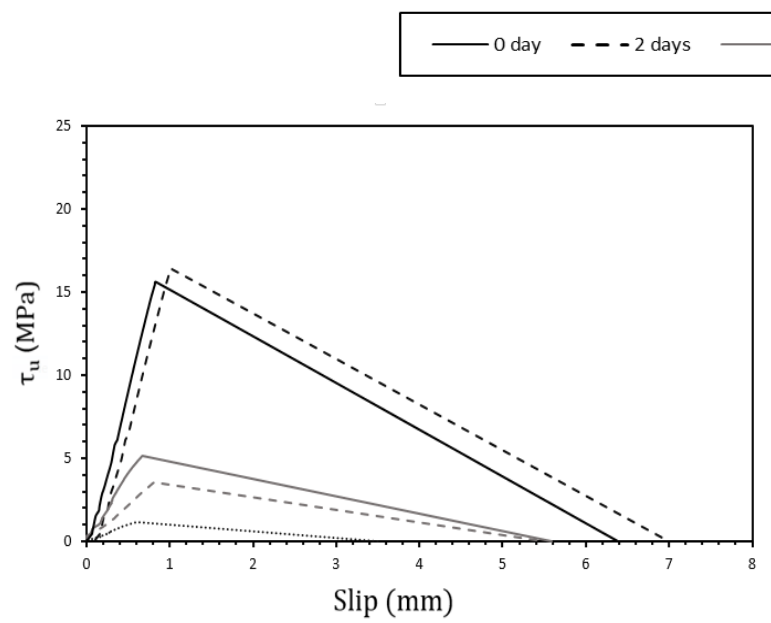

(a)

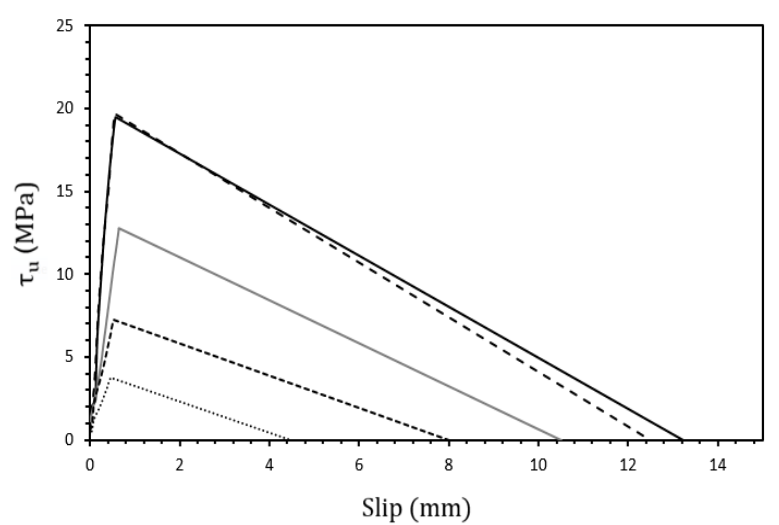

(b)

Fig. 10. Bond stress versus slip for specimens having $\varnothing 20 \mathrm{~mm}-\mathrm{I}_{\mathrm{d}}=100 \mathrm{~mm}$ and (a). R100 and (b). R100-NS3.

\section{3. 2. Influence of nano silica on bond strength}

Fig. 11 presents how the bond strength can be influenced by adding NS to both normal and RCA concretes at various corrosive periods. As it can be seen that the bond strength slightly reduced for non-corroded specimens when normal aggregate was replaced by RCA, reporting between $6 \%$ and $11 \%$ bond decrease. This reduction probably related to the presence of cracks on the surface of RCA, affecting the adhesive force and the mechanical interlock of RCA concrete. Nevertheless, much more bond degradation was observed for RCA concretes after being exposed to corrosive environmental conditions to reach less than half at 15 days of corrosion, in comparison to conventional concrete. This was supported by the results presented in a recent study [32]. By partially replacing cement in normal concrete with $1.5 \% \mathrm{NS}$, the bond strength for un-corroded specimens $\left(\varnothing 12 \mathrm{~mm}-\mathrm{I}_{\mathrm{d}}=60 \mathrm{~mm}, \varnothing 12 \mathrm{~mm}\right.$ $\left.l_{d}=167 \mathrm{~mm}, \varnothing 20 \mathrm{~mm}-I_{d}=100 \mathrm{~mm}\right)$ increased by $11 \%, 8 \%$ and $12 \%$, respectively. Better bond enhancements were stated after adding the same quantity of NS to fully RCA concretes, $9-21 \%$. However, the influence of adding 1.5\% NS became more pronounced after exposure to corrosion, especially with the increase of RCA contents. For instance, the bond strength for R100- NS1.5 having $100 \mathrm{~mm}$ bonded bar length achieved over three times higher bond, after 15 days corrosion, compared to the same mixture without NS, achieving about $2 \%$ higher than conventional concrete. This huge difference at this stage might be ascribed to the availability of wide cracks in RCA specimens, while those cracks were almost disappeared in NS mixtures. Therefore, the addition of $1.5 \%$ NS was evidently sufficient to recover the poor bond performance occurred after being subjected to chloride severe conditions. The superior performance of NS is primarily attributed to the double effect of NS in 
enhancing the bond strength as well as corrosion resistance. This probably can be attributed to the enhancement of compressive strengths resulting from the formation of supplemental C-S-H gels, in addition to the effectiveness of NS particles in retarding the ingress of chloride ions into steel/concrete interface by acting as a filler to the tiny pores available in the matrix. Thus, the degradation of bond during the progression of corrosion process was impeded and delayed. By increasing the level of NS from $1.5 \%$ to $3 \%$, the bond enhancement ratio increased in a narrow range (4\%-9\%) for all specimens free from corrosion, On the other hand, the bond resistance of using the same quantity (3\%) was markedly promoted with increasing both RCA content and exposure period to salt solutions. Therefore, NS particles were more efficient in terms of bond performance with fully RCA replacement rather than normal concrete, likewise the observations obtained from other properties (i.e. compressive strength and corrosion resistance). This is primarily attributed to the higher capillary spaces and larger pores available in the microstructure of RCA concrete. Therefore, NS particles can easily fill up these spaces, in addition to the ability of such particles in reacting with a large amount of $\mathrm{Ca}(\mathrm{OH})_{2}$ found in $\mathrm{RCA}$ concrete, and producing more C-S-H gel. It is also observed that the majority of NS specimens made with longer bonded length $(167 \mathrm{~mm})$ and did not expose to corrosion or slightly corroded failed due to steel bar rupture, rather than bond failure; for those specimens, no bond strength is reported. Another observation from these results is that the specimens having $\varnothing 20 \mathrm{~mm}-\mathrm{l}_{\mathrm{d}}=100 \mathrm{~mm}$ were more sensitive to the influence of RCA and NS contents in terms of bond strength rather than others since higher relative rib areas were reported with such specimens, enhancing the transfer of force between steel and surrounding concrete. 


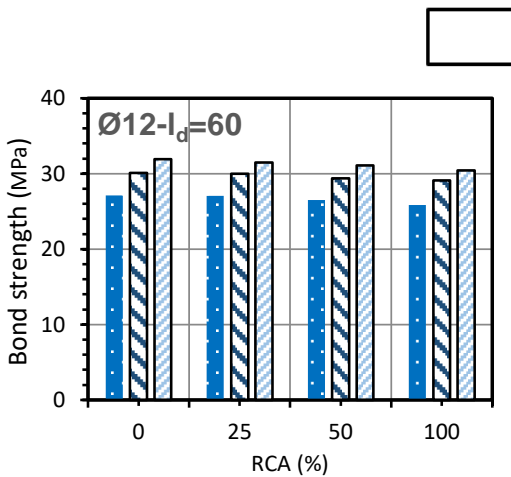

\section{$0 \% \mathrm{NS} \quad \mathbf{1 . 5 \% N S} \square 3 \% \mathrm{NS}$}
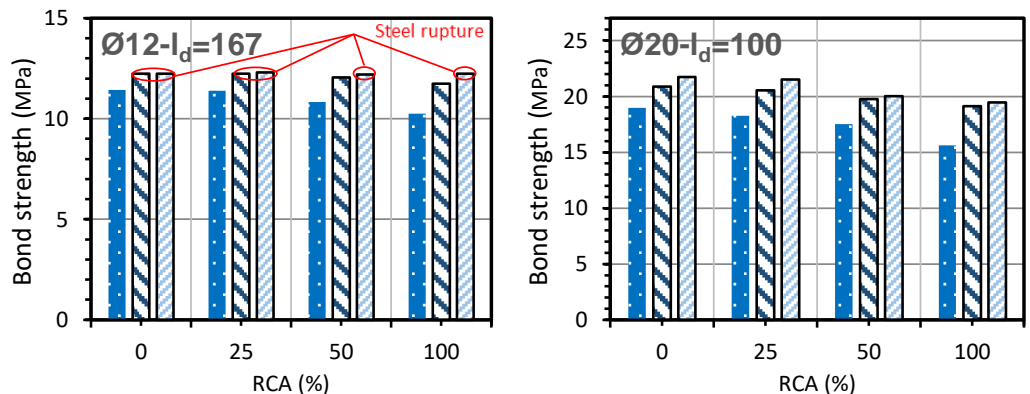

(a)
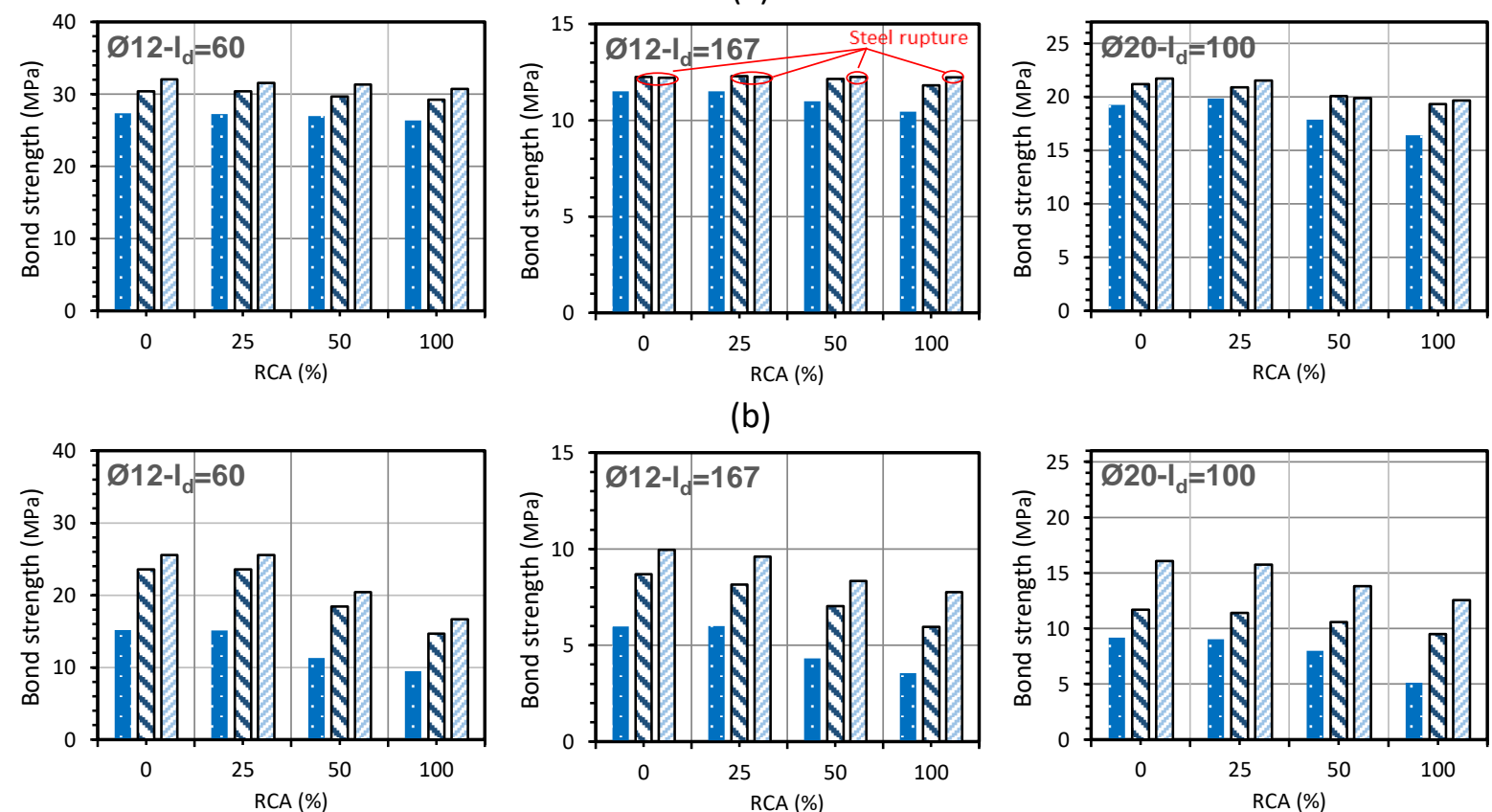

(b)
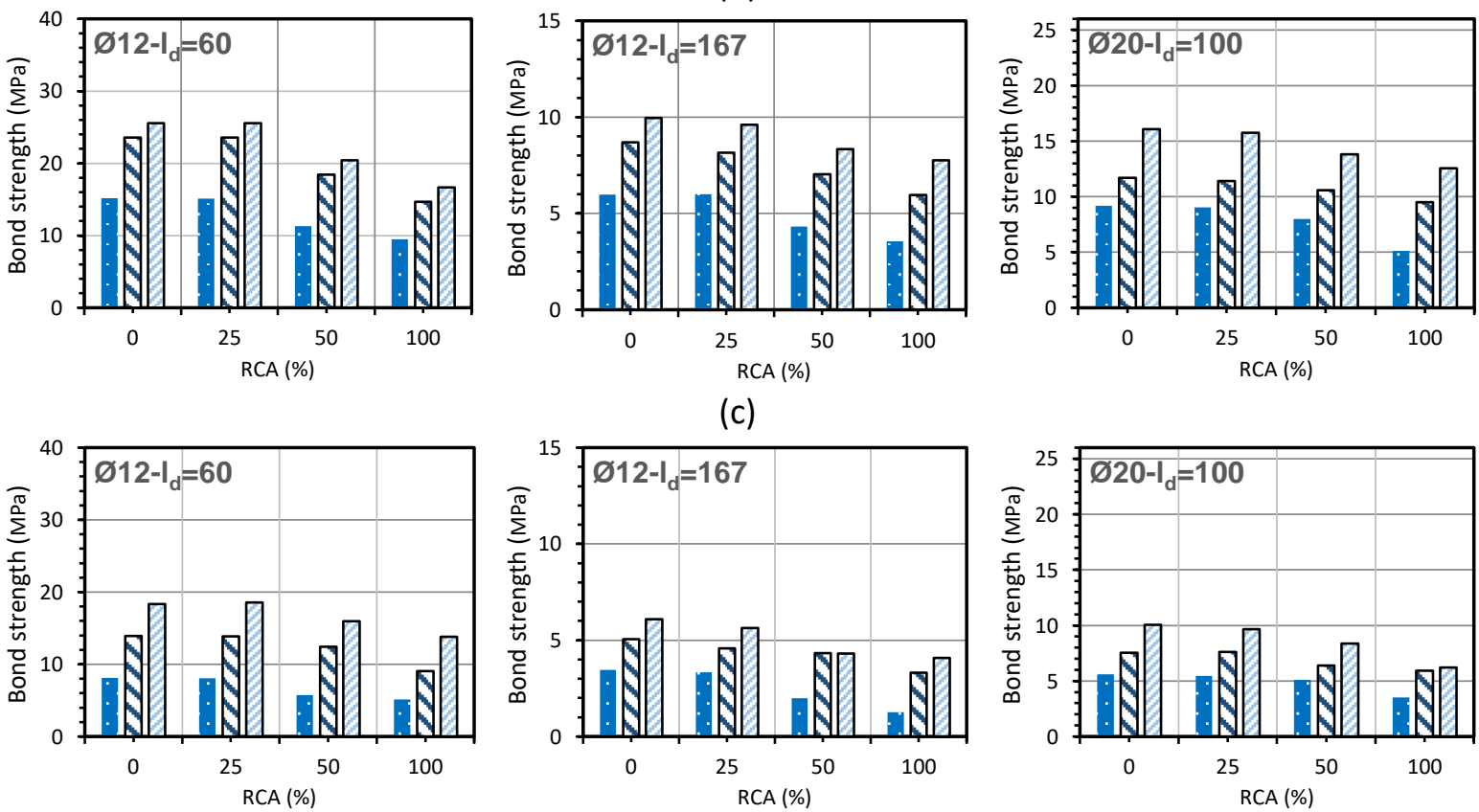

(c)
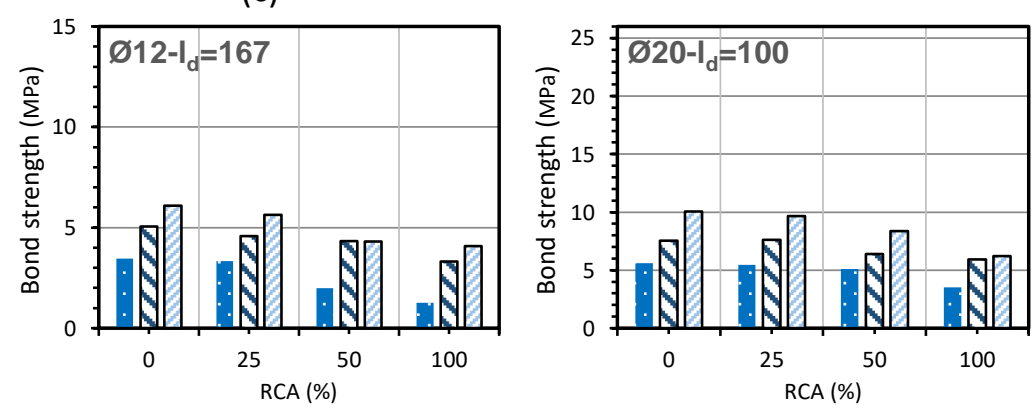

(d)
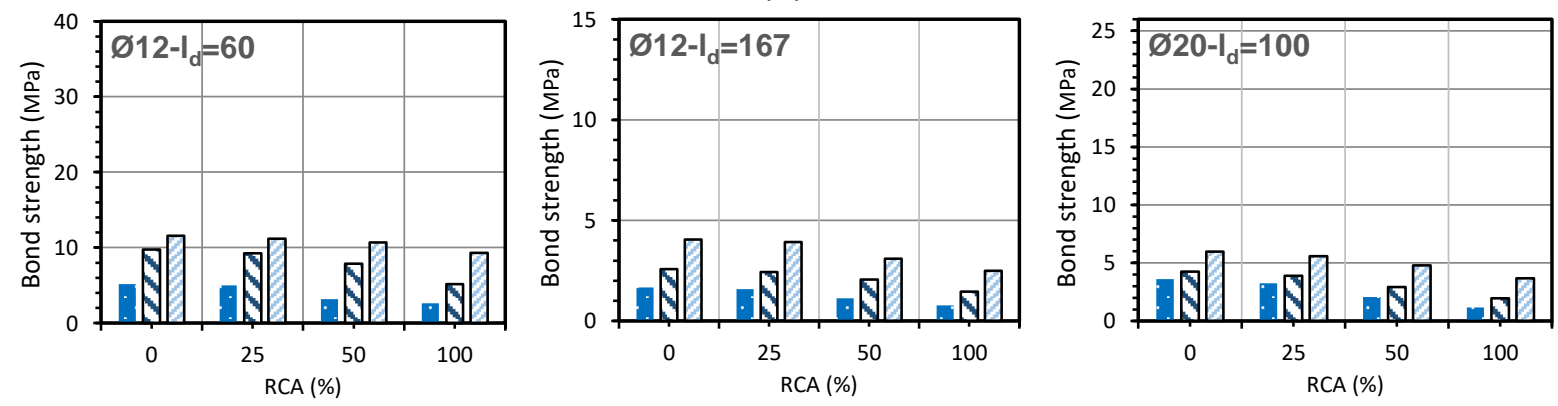

(e)

Fig. 11. Bond strengths of specimens exposed to corrosion for: (a) 0 day, (b) 2 days, (c) 5 days, (d) 10 days, (e) 15 days. 


\section{3. 3. Effect of corrosion level on bond strength}

This section is mainly focused on how the ultimate bond between steel reinforcement and concrete can be influenced by corrosion products, regardless of mixtures components (i.e. RCA or NS). Even though several studies have been conducted on this area, varying levels of effect were reported in addition to disagreement regarding the critical corrosion value [6, 33-34]. Fig. 12 presents the effect of corrosion on bond strength for $60 \mathrm{~mm}, 167 \mathrm{~mm}$ and $100 \mathrm{~mm}$ embedment length specimens as a ratio of the bond strength of corroded bars to that without corrosion. From the presented results, it can be obviously seen that the bond strength slightly promoted up to about $6 \%$ enhancement with a little amount of corrosion products, agreeing with the similar observations reported by other authors for normal concrete specimens $[5,35]$ as well as RCA concrete [32]. However, this improvement seems much smaller than that obtained in other studies as the improvement exceeded $20 \%$ [36] and reached $40 \%[20,37]$, which might be explained by the larger concrete cover used in the current work (90-94mm) as well as higher compressive strength, leading to reduction of stresses from corrosion products. It is important to note that there is still no consensus about the critical corrosion rate as it has been reported between $0.5 \%$ and $2.4 \%$, associated to the difference in details of specimens' tested as well as the direct current applied for accelerated steel corrosion. Accordingly, the enhancement in the current study was reported up to almost $2 \%$ corrosion rate, while further corrosion resulted in a significant reduction in the bond strength. The increased roughness of steel surface and the development of radial stresses at steelconcrete interface due to the formation of a small layer of rust around the bar could explain why the frictional bond forces increase. A considerable loss in bond was observed with the propagation of corrosion, reporting between $10-80 \%$ degradation at corrosion level $2.5-10 \%$. This likely happened due to the appearance of internal cracks, which could extend up to the external surface of concrete. During this stage, the passivity protective layer around reinforcement was destroyed in addition to the decay of ribs height. In the highly advancing levels of corrosion (above $10 \%$ weight loss), the residual bond resistance did not exceed $20 \%$ for the majority of specimens. This serious degeneration is primarily attributed to the appearance of longitudinal cracks on accompanied by the losing of reinforcement lugs. 


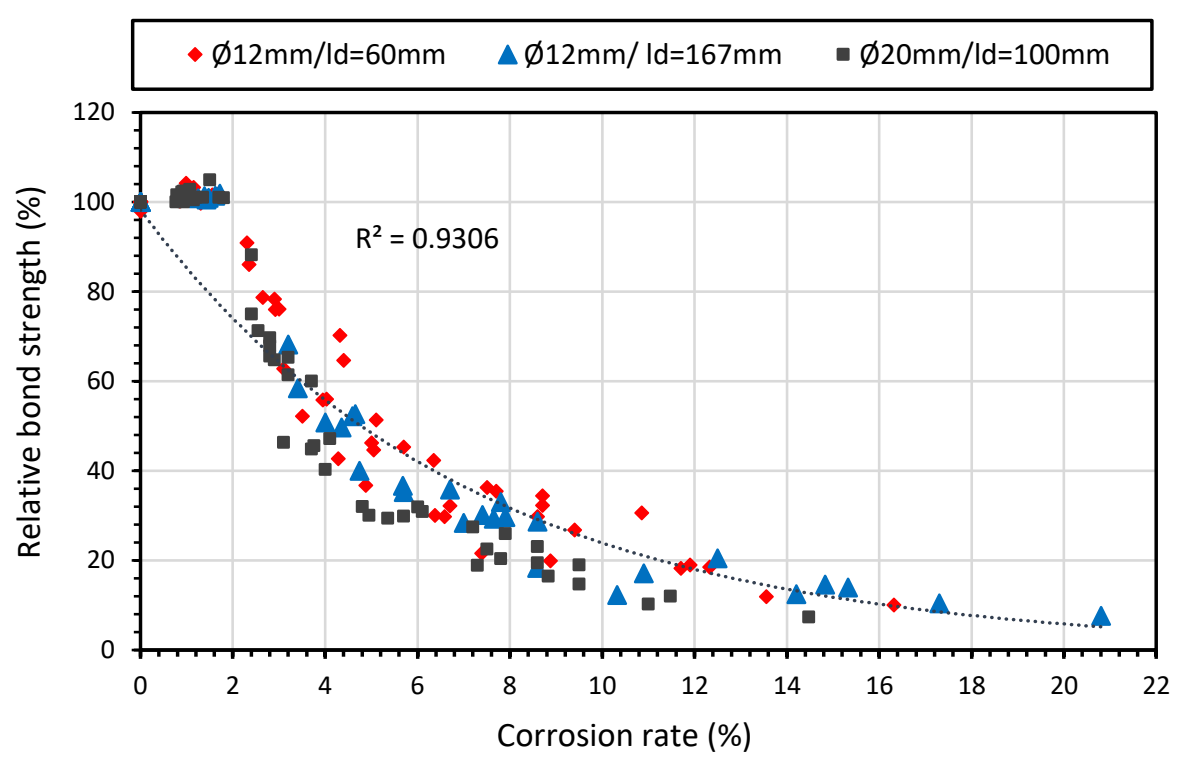

Fig. 12. Relationship between corrosion rate and relative bond strength.

\section{3. 4. Effect of embedment length on bond strength}

Fig. $13(a-b)$ exhibits the influence of bonded length for specimens prepared with $12 \mathrm{~mm}$ bar diameter before and after exposure to corrosive environments (15 days). As shown in Fig. 13 (a), by increasing the un-corroded bonded length from 5 to 13 times of bar diameter, the ultimate bond strengths considerably decreased by $37 \%$ and $35 \%$ for R50 and R100 mixture, respectively. These findings are supported by a previous work [1] that stated between $30-50 \%$ reductions in bond resistance of RCA concrete as the bonded length was doubled to be 10 times of bar size. The increase of non-linear distribution of bond stresses along larger embedment length might explain the drop in bond resistance, and therefore lower bond stresses were distributed with the increase of bar length. This distribution could reach a neglected value (almost zero) at a certain point, and hence the increase of bonded length beyond this point would not cause any difference on the bond performance [38]. On the other hand, no exact reduction rates were reported for the majority of specimens made with NS due to steel rupture with the longer embedment length $(13 \varnothing)$. In the advancing levels of corrosion (15 days), more degradation in bonding was observed with longer bonded length, especially for mixtures made without NS as shown in Fig 13(b), owing to the presence of longitudinal cracks, restricting force transfer between reinforcement and surrounding concrete, whereas those containing NS showed almost the same rate. By increasing the embedment length from 5 to 13 times of bar diameter, the mode of failure was also changed from pull-out mode to splitting in concrete. 


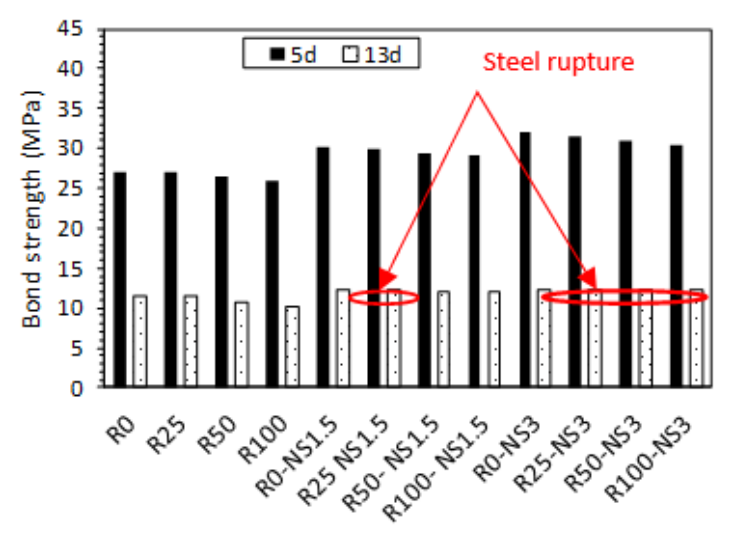

(a)

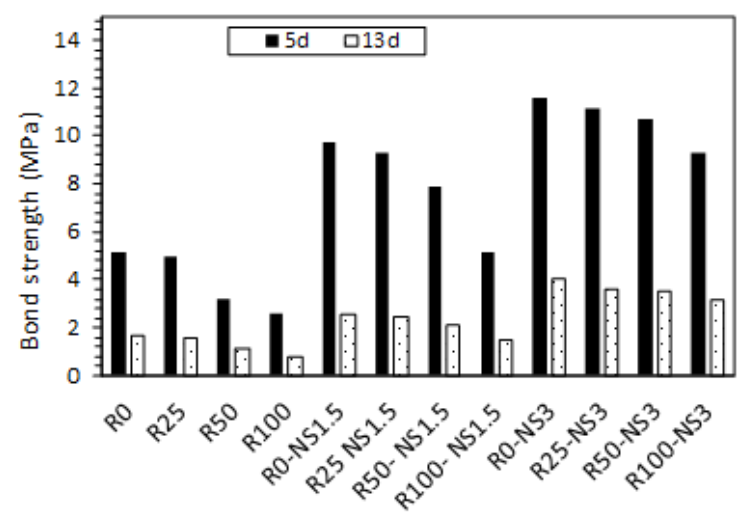

(b)

Fig. 13. Effect of embedment length on bond strength: (a) before corrosion (b) after corrosion.

\section{3. 5. Effect of bar diameter on bond strength}

In the present study, the influence of bar diameter was investigated for bars (12mm and 20mm) using two different cases of bond length. Whilst in the first case the comparison was made using the same bonded area $\left(6280 \mathrm{~mm}^{2}\right)$, in the second case the embedment length was chosen to be five times of bar diameter, as recommended by RILEM specification [30]. By using the same bonded area, the results indicated that the bond resistance provided by $\varnothing 12 \mathrm{~mm}$ reported $60-65 \%$ of the bond obtained from larger bars $(20 \mathrm{~mm})$ as shown in Fig. 14(a). Even though a similar trend was anticipated for un-corroded NS specimens, nevertheless, the comparison was not obtained as bar rupture occurred in $12 \mathrm{~mm}$ steel reinforcement before de-bonding. These results might be explained by the influence of relative rib area of steel as it plays an influential role in enhancing bond mechanism by blocking the ribs in concrete. The relative rib area $\left(f_{R}\right)$ can be simply described by the specific combination of ribs height and bar spacing [39], which can be found different from bar diameter to another. In this study, the relative rib area for $\varnothing 20 \mathrm{~mm}(0.16)$ reported approximately $20 \%$ higher than found in $\varnothing 12 \mathrm{~mm}$, agreeing with other authors [37] who reported $40 \%$ higher bond when $f_{R}$ raised from 0.04 to 0.1 , whereas another study [41] stated $24 \%$ higher bond resistance as $f_{R}$ doubled from 0.08 to 0.16 . The difference in bond load might be also affected by reaching $\varnothing 12 \mathrm{~mm}$ to the yielding stage before the occurrence of bond failure, and therefore the frictional properties and ribs geometry would be affected [41]. Specimens probably became less sensitive to bar diameter after being progressively corroded, which can be justified by the erosion of steel lugs for both bars, and therefore the transferred force between reinforcement and concrete would be reduced. The change in bar diameter from $12 \mathrm{~mm}$ to $20 \mathrm{~mm}$ also directly caused a change in the failure mode from pull-out to be split. 
The results obtained from the other situation ( 5 times of bar diameter) showed a notable reduction in the maximum bond strength for larger bar diameter $(20 \mathrm{~mm})$ for all specimens tested either corroded or un-corroded. As depicted in Fig. 14(b), the bond strength for $20 \mathrm{~mm}$ non-corroded bars reported about $63 \%$ of those made with $12 \mathrm{~mm}$, in agreement with previous investigations [1]. This phenomenon is attributed to the increase of bleeding water trapped underneath the reinforcement, resulting in larger numbers of voids, which in turn caused a reduction in the contact area between steel and surrounding concrete, and therefore the bond strength would be eventually reduced [42, 43]. Almost similar behaviour was observed after exposure to aggressive environments as reported by others [39].

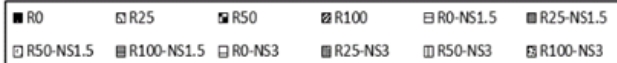

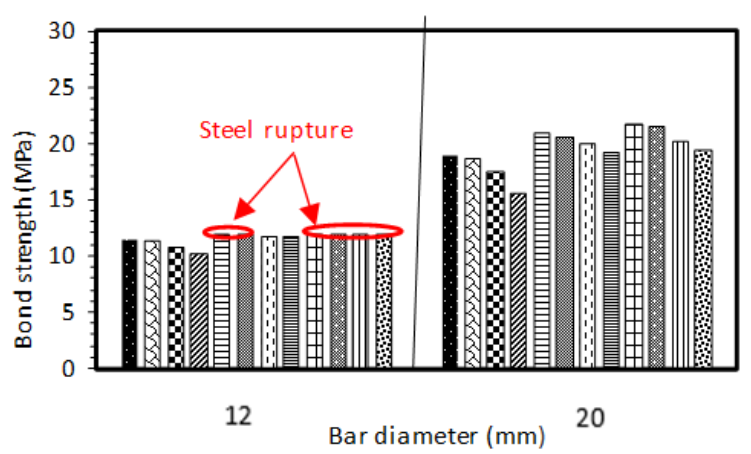

(a)

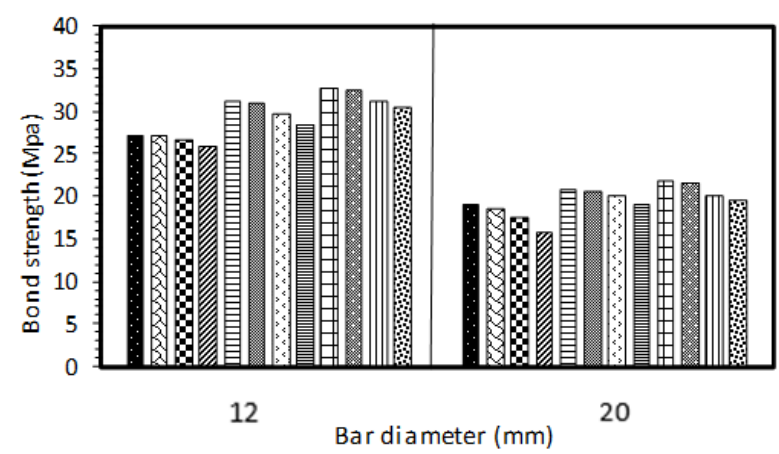

(b)

Fig. 14. Effect of bar diameter on bond strength using: (a) the same bonded area; (b) $\mathrm{l}_{\mathrm{d}}=5 \varnothing$

\section{3. 6. Bond failure mechanism}

According to the obtained results, four types of failure were observed from pull-out test during the present study as shown in Fig. 15, based on concrete strength, corrosion level in addition to the bonded length and bar diameter of steel. Pull-out failure mode was dominant for specimens having $\varnothing 12 \mathrm{~mm}$ and smaller embedded length $(60 \mathrm{~mm})$, before and after being slightly corroded, owing to the availability high level of confinement provided by the large concrete cover $(94 \mathrm{~mm})$. In this case, the shear force resulted from concrete surpassed the radial force generated from reinforcement, and therefore the steel ribs would crush concrete keys placed between steel lugs. After ten days of corrosion acceleration, some specimens interestingly failed in pull-out mode accompanied by splitting mode as shown in Fig 15 (b). This might occur due to the presence of narrow cracks making the radial forces of reinforcement almost equal with the confining action. However, the mode of failure changed to splitting for specimens that highly corroded due to the existence of wide cracks. As the embedment length increased from $5 \varnothing$ to $13 \varnothing$, two types of failure were observed; steel bar rupture or concrete splitting failure. Whilst the former 
mode was dominant for non-corroded NS specimens and those slightly corroded as shown in Fig. 15(c), splitting mode was observed with medium and highly corroded specimens as well as those made without NS, indicating that the radial force generated from steel reinforcement overcame the confining action resulting from the tensile strength of concrete (See Fig. 15(d)). In the case of specimens having $\varnothing 20 \mathrm{~mm}, l_{d}=100 \mathrm{~mm}$, the latter mode was predominant on all specimens tested regardless of corrosion rate.

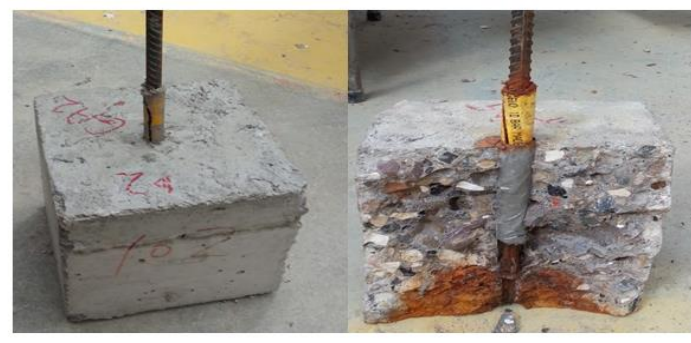

(a)

(b)

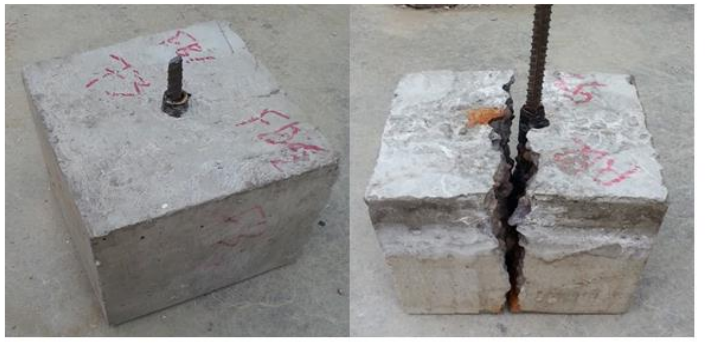

(c)

(d)

Fig. 15. Bond failure modes obtained from pull-out tests.

\section{Bond strength equations in code provisions and empirical equations}

\section{1. Comparison of experimental bond strength of un-corroded bars with existing models}

For comparison purposes, several equations have been proposed to estimate the bond strengths between steel and concrete taking into consideration the influence of main parameters (i.e. compressive strength, concrete cover, bar diameter and embedment length). These models are summarised in Table 6 , and compared with the experimental results to evaluate the performance of these models as presented in Fig. 16, whilst a $45^{\circ}$ line was plotted to represent the same experimental and predicted bond values. It should be noticed that such models were mainly proposed for normal concrete specimens. In order to properly compare the results with these models, a correction factor was adopted (0.8-0.82) for converting the strength of cube into cylinder strength [44]. 
Table 6. Existing models for predicting bond strengths.

\begin{tabular}{|c|c|}
\hline Reference & Model \\
\hline CEB-FIP (2010) [45] & $\begin{aligned} \tau_{u} & =2.5 \sqrt{f_{c}^{\prime}} \quad \text { at pull-out failure; } \\
\tau_{u} & =7.0\left(\frac{\sqrt{f_{c}^{\prime}}}{25}\right)^{0.25} \quad \text { at splitting failure }\end{aligned}$ \\
\hline $\begin{array}{l}\text { Australian Standard } 3600 \\
\text { (2004) [46] }\end{array}$ & $\left.\tau_{u}=0.265 \sqrt{f_{c^{\prime}}^{\prime}}\left(\left(\frac{c}{d_{b}}\right)+0.5\right)\right)$ \\
\hline Orangun et al., (1977) [47] & $\tau_{u}=0.083045 \sqrt{f_{c}^{\prime}}\left(1.2+3.0\left(\frac{c}{d_{b}}\right)+50\left(\frac{d_{b}}{l_{d}}\right)\right)$ \\
\hline Darwin et al., (1992) [48] & $\begin{array}{c}\tau_{u}=0.083045 \sqrt{f_{c}^{\prime}}\left(1.06+2.12\left(\frac{c}{d_{b}}\right)\right) \cdot\left(0.92+0.08\left(\frac{C_{\max }}{C_{\min }}\right)+75\left(\frac{d_{b}}{l_{d}}\right)\right) \\
\text { where } C_{\min }=\min \left(C_{x}, C_{y}, C_{s} / 2\right) \text {, while } C_{\max }=\max \left(\min \left(C_{x}, C_{s} / 2\right), C_{y}\right) \text {, which } C_{x} \text { is the } \\
\quad \text { side cover, } C_{y} \text { is the bottom cover, and } C_{s} \text { is the spacing between the bars }\end{array}$ \\
\hline $\begin{array}{c}\text { Esfahani \& Rangan (1998) } \\
\text { [49] }\end{array}$ & $\begin{array}{l}\tau_{u}=8.6 \frac{C / d+0.5}{C / d+5.5} f_{c t} \\
\text { where } f_{c t}(\mathrm{MPa}) \text { is the tensile strength of concrete taken as } 0.55 \sqrt{f_{c}^{\prime}} \text {. }\end{array}$ \\
\hline
\end{tabular}

As can be seen from Fig. 15 that varying levels of performance were obtained by applying these equations. It can be noticed that the equation suggested by Darwin et al. [48] showed the closest correlation with the experimental results, with a mean ratio of 1.06 and a standard deviation (S.D) of 0.189. Esfahani \& Rangan [49] model was less accurate, especially in the case of higher bonded length with a mean value of 1.08 and S.D of 0.43 , since the variation in embedment length was not considered in this equation. The equation proposed by Orangun et al. [47] showed under-predicted values for specimens made with a short embedment length (5 times of $\varnothing$ ) for either bar diameter $12 \mathrm{~mm}$ or $20 \mathrm{~mm}$; however, the results were over-estimated for longer embedment length (13 times of $\varnothing$ ), presenting 0.86 mean value and 0.27 S.D. The predicted values obtained from CEB-FIP model [45] showed conservative results (Mean=0.75, S.D=0.146), showing under-predicted values in the case of smaller bar diameter, while better predictions were obtained with larger bar diameter $(20 \mathrm{~mm})$. The Australian Standard (AS3600) [46] presents a reasonable correlation with the experimental results (Mean $=0.82$, S.D=0.37), since the influence of compressive strength, concrete cover and bar diameter were only considered in the equation. The over-estimation observed with the most of these models in the case of longer bonded length may be attributed to the nonlinear distribution of bond stresses along the bonded length of bars. 


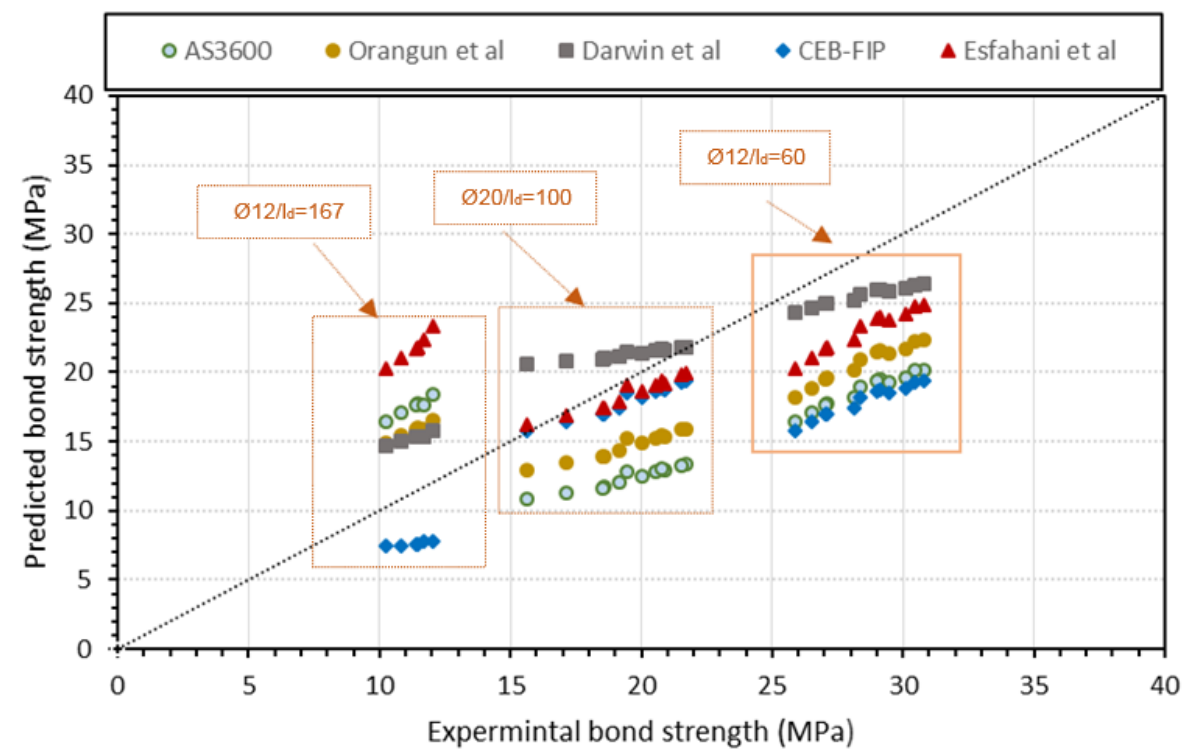

Fig. 16. Experimental versus predicted bond strengths.

\section{2. Predicting bond degradations due to corrosion}

The effect of corrosion on bond strength has been assessed by several researchers [50-53] and has been expressed as a ratio between bonds after exposure to corrosion products to the original bond (without corrosion) as follow:

$$
K_{t}=\frac{\tau_{c}}{\tau_{0}}
$$

where $K_{t}$ is the relative bond strength, $\tau_{0}$ is the reference bond strength of un-corroded steel bars, and $\tau_{c}$ is the bond strength of steel bars exposed to corrosion.

In the present work, six models were used for predicting the relative bond $\left(K_{t}\right)$ as demonstrated in Table. 7 , and the results calculated from these formulas were compared with those experimentally obtained as shown in Fig 17. 
Table. 7. Models for predicting the relative bond strengths due to corrosion.

\begin{tabular}{|c|c|}
\hline References & Normalised equation \\
\hline Cabrera (1996) [35] & $K_{t}=1-5.6 \eta$ \\
\hline Auyeung et al. (2000) [34] & $K_{t}=e^{-32.5 \eta}$ \\
\hline Lee et al. (2002) [50] & if $\begin{aligned} f_{c}^{\prime} \leq & 21 M P a, K_{t}=1, \text { for } \eta<\frac{\ln \left(\left(0.34 f_{c}^{\prime}-1.93\right) / 5.21\right)}{-0.0561} \% \\
K_{t}= & \frac{5.21 e^{-0.0561 \eta}}{0.34 f_{c}^{\prime}-1.93} \text { for } \eta>\frac{\ln \left(\left(0.34 f_{c}^{\prime}-1.93\right) / 5.21\right)}{-0.0561} \\
& \text { if } \quad f_{c}^{\prime}>21 \mathrm{MPa}, \quad K_{t}=\frac{5.21 e^{-0.0561 \eta}}{5.21}\end{aligned}$ \\
\hline Chung et al., (2008) [51] & $\begin{array}{c}K_{t}=1 \text { for } \quad \eta \leq 2.0 \% \\
K_{t}=\frac{24.7 \eta^{-0.55}}{16.87} \quad \text { for } \quad \eta>2.0 \%\end{array}$ \\
\hline Bhargava et al., (2007) [52] & $\begin{array}{c}K_{t}=1.192 \eta^{(-0.117 \eta)} \quad \text { if } \quad \eta>1.5 \% \\
K_{t}=1.0 \quad \text { if } \quad \eta \leq 1.5 \%\end{array}$ \\
\hline Kivell (2012) [53] & $\begin{array}{ccc}K_{t}=e^{-7.61(\eta-2.4 \%)} & \text { if } & \eta \leq 1.0 \% \\
K_{t}=1.2 e^{-0.076 \eta} & \text { if } & \eta>1.0 \%\end{array}$ \\
\hline
\end{tabular}

Note: $\mathrm{K}_{\mathrm{t}}=$ relative bond strength; $\eta$ = corrosion rate.

From Fig.17, it is apparent that none of these models exhibited a high accuracy in predicting the relative bond strength, in particular, Lee et al., and Kivell et al. models $[50,53]$, which are highly over-estimating $K_{t}$ with a mean value of 0.68 and 0.64 , respectively. The over-estimation was also observed with the formulas proposed by Chung et al. [51], Bhargava et al. [52], and Cabrera et al. [35], with a coefficient of determination $0.73,0.76$ and 0.74 , respectively, since the suggested loss in bond due to corrosion tends to gradually decrease by increasing the level of corrosion. This trend does not appropriately match the significant degradation occurred with the experimental specimens, especially after the appearance of tiny cracks on specimens' surface. On the other hand, the findings obtained from Auyeung et al formula [34] show under-estimated values compared to the actual results, giving the best performance with a coefficient of determination of 0.81 . 


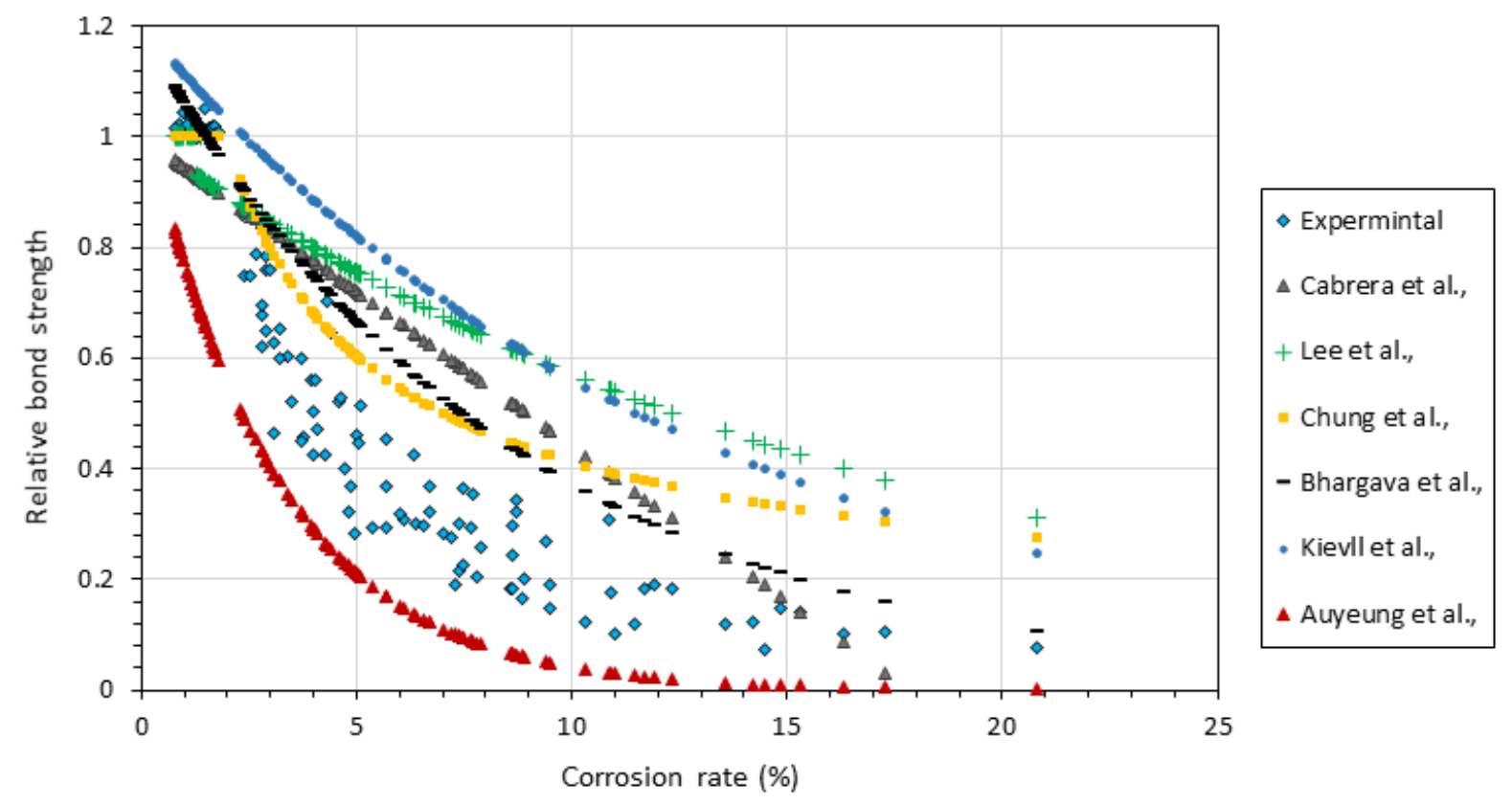

Fig. 17. Comparison of relative bond strength calculated by models to the experimental results.

To improve the theoretical prediction of the effect of the corrosion rate on bond strength, a regression analysis was performed to obtain a new relative bond strength coefficient, $\mathrm{K}_{\mathrm{t}}$, using the experimental data obtained in this study as well as the database collected by Fig et al, (2016) [54]. The experimental data collected by Fig et al. (2016) [54] cover variations of parameters, including concrete specimen size, bar diameter, concrete cover thickness, concrete strength, and corrosion level. However, it should be noted that all specimens collected in the database were prepared for natural aggregate and bond strength was obtained from pull-out test. Therefore, the following formula is proposed to predict the normalised bond strength, assuming that the increase in bond strength up to $2 \%$ mass loss is negligible:

$$
K_{t}=1.0 \quad \text { if } \quad \eta \leq 2.0 \% ; \quad K_{t}=1.69 \eta^{(0.913)} \quad \text { if } \quad \eta>2.0 \%
$$

where $\eta$ is the corrosion rate, and $K=\left(\tau_{c} / \tau_{0}\right)$ is the bond strength of steel bars exposed to corrosion relative to the reference bond strength of un-corroded steel bar.

The proposed formula has been validated through a comparison with the current experimental results as shown in Fig. 18. It can be clearly seen that the proposed formula closely predicts the bond degradation due to corrosion with a mean ratio of predicted to experimental bond strengths of 0.99 , a standard deviation of 0.17 and a coefficient of variation of 0.17 . 


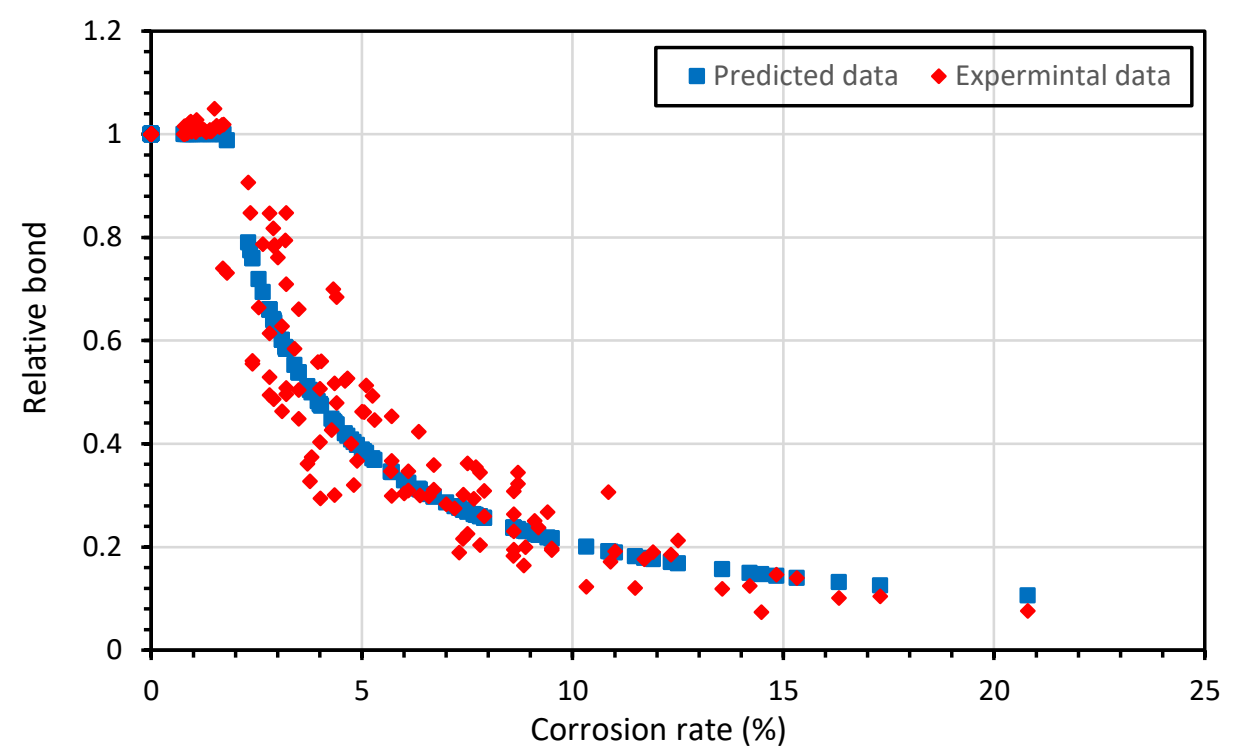

Fig. 18. Comparison of the predicted relative bond to the experimental results.

\section{Economic impact of using nano silica in recycled aggregate concrete}

Although the use of NS enhanced many mechanical properties of RCA concrete as observed in the current investigation and others [29,55], the initial cost of concrete is likely to be increased due to the addition of NS. Other economic and environmental matters of adding NS to concrete that are expected to over-weight such initial cost increase are discussed below:

- Firstly, the cost of nano silica is not too expensive compared with other nano materials as emphasised by the wide spread use of nano silica in recent years due to its known beneficial properties.

- As a little amount of NS is mostly used in concrete (less than $3 \%$ ), the total cost of concrete would not be significantly affected.

- The cost of RCA is cheaper than that of normal aggregate that can partially mitigate the increase of initial cost due to the addition of NS.

- The transportation cost of RCA becomes more economical than normal aggregate, since RCA is mostly transported from local quarries, whilst transporting normal aggregate is dependent on the location of its source.

- Another factor is associated to the escalated cost of landfilling of RCA if not used due to stricter environmental regulations, especially in areas of increasingly scarce landfills. 
- Furthermore, the addition of NS to RCA concrete is likely to enhance the concrete durability in comparison with the control concrete, as observed from the current results, and therefore the life cycle of such concrete structures would be probably extended, reducing the life-cycle cost of RCA concrete with NS.

- Moreover, the use of RCA can further contribute to mitigating the expected increased price of natural aggregate as about $60 \%$ of natural limestone resources could be saved [56], accompanied by reducing the cost required to address the emissions of $\mathrm{CO}_{2}$ since about 15$20 \%$ of these emissions would be reduced [57].

- Finally, the price of NS is expected to become cheaper with their mass production.

\section{Conclusions}

In the present study, the influence of adding NS to concretes prepared with various levels of RCA was experimentally investigated in terms of bond strength with steel bars at various levels of corrosion as well as corrosion resistance under corrosive conditions. Based on the obtained results, the following conclusions can be drawn:

- The addition of nano silica to normal and RCA concretes showed an improvement of compressive strength up to $40 \%$ at 28 days, however, the strength gain obtained by adding NS to RCA concretes was higher than that for conventional concretes. In addition, NS was appreciably sufficient to recover the decrease occurred due to RCA content and achieved even higher strength, in comparison to control concrete.

- The corrosion level significantly propagated with the increase of RCA quantity in concrete, especially under advancing levels of corrosion exposure, owing to its higher permeability and water absorption, nevertheless, NS particles evidently recuperated this phenomenon by considerably minimising the pores available in mixtures.

- The use of a small quantity of NS (1.5\%) showed between $8-21 \%$ bond enhancements with both normal and RCA concretes in non-corrosive conditions; however, much better influence (more than three times) was observed with increasing corrosion period, reflecting the double counting effect of NS particles in enhancing the bond strength as well as corrosion resistance.

- NS particles were more effective with RCA concrete mixtures compared with normal concretes, achieving higher enhancement rate in terms of bond and corrosion resistance due to the accessibility of NS in dealing with the larger pores available in RCA concretes 
- NS was superbly effective in recovering the poor performance in bond strength and corrosion resistance for RCA concretes, achieving higher values than the reference concrete.

- By doubling the content of NS (3\%), the bond resistance slightly enhanced for non-corroded specimens, whilst its influence becomes more pronounced by increasing RCA content as well as exposure time to corrosion.

- The bond performance of RCA and NS concretes was seriously influenced by the level of corrosion; while the bond resistance slightly increased up to about $6 \%$ enhancement with a small amount of corrosion (2\% mass loss), further corrosion led to a significant bond degradation.

- The effect of bar diameter is directly related to the bonded length; unexpectedly, higher bond strengths obtained with larger diameters for all mixtures in the case of using the same surface area due to the influence of relative ribs area. On the other hand, an opposite trend was observed when the bonded length was taken as a ratio of bar diameter. Higher decreasing rates in bond strength were observed when the embedment length increased from 5 to 13 times of bar diameter.

- Darwin' Model exhibited the highest accuracy for predicting the bond strength of un-corroded bars embedded in concrete, whilst the formula suggested by Auyeung et al., provided a better predicting of bond degradation due to corrosion.

\section{Acknowledgments}

The authors wish to tank MONO BROS Company in Leeds (UK) for suppling recycled aggregates used in this research. The authors also gratefully acknowledge Akzonobel Company for providing nano silica used in this research.

\section{References}

1. Pour, S.M. and M.S. Alam. Investigation of compressive bond behavior of steel rebar embedded in concrete with partial recycled aggregate replacement. in Structures. 2016. Elsevier.

2. Kim, S., et al., Bond between high strength concrete with recycled coarse aggregate and reinforcing bars. Materials Research Innovations, 2014. 18(sup2): p. S2-278-S2-285.

3. De Brito, J. and N. Saikia, Recycled aggregate in concrete: use of industrial, construction and demolition waste. 2012: Springer Science \& Business Media.

4. Behera, M., et al., Recycled aggregate from $C \& D$ waste \& its use in concrete-A breakthrough towards sustainability in construction sector: A review. Construction and building materials, 2014. 68: p. 501-516.

5. Ouglova, A., et al., The influence of corrosion on bond properties between concrete and reinforcement in concrete structures. Materials and Structures, 2008. 41(5): p. 969-980.

6. Yang, H., et al., A study on the bond behavior of corroded reinforced concrete containing recycled aggregates. Advances in Materials Science and Engineering, 2015. 2015. 
7. Alhawat, $\mathrm{M}$, and $\mathrm{A}$, Ashour, Bond strength between corroded steel reinforcement and recycled aggregate concrete. Structures. 2019 (19).

8. Tateyashiki, H., et al., Properties of concrete with high quality recycled aggregate by heat and rubbing method. Proc. JCl, 2001. 23(2): p. 61-66.

9. Tam, V.W., C.M. Tam, and K.N. Le, Removal of cement mortar remains from recycled aggregate using pre-soaking approaches. Resources, Conservation and Recycling, 2007. 50(1): p. 82-101.

10. Katz, A., Treatments for the improvement of recycled aggregate. Journal of materials in civil engineering, 2004. 16(6): p. 597-603.

11. Spaeth, V. and A.D. Tegguer, Improvement of recycled concrete aggregate properties by polymer treatments. International Journal of Sustainable Built Environment, 2013. 2(2): p. 143-152.

12. Vázquez, E., Progress of recycling in the built environment: final report of the RILEM Technical Committee 217-PRE. Vol. 8. 2012: Springer Science \& Business Media.

13. Wang, H.-I., et al., Improving performance of recycled aggregate concrete with superfine pozzolanic powders. Journal of Central South University, 2013. 20(12): p. 3715-3722.

14. Kong, D., et al., Effect and mechanism of surface-coating pozzalanics materials around aggregate on properties and ITZ microstructure of recycled aggregate concrete. Construction and Building Materials, 2010. 24(5): p. 701-708.

15. Alhawat, M. et al., Properties of concrete incorporating different nano silica particles. Materials Research Innovations. 2019: 1-12.

16. Shaikh, F., S. Supit, and P. Sarker, $A$ study on the effect of nano silica on compressive strength of high volume fly ash mortars and concretes. Materials \& Design, 2014. 60: p. 433-442.

17. British Standard Institution, BS.197-1: 2011. Cement, Composition, Specifications and Confor ity Criteria for Common Cements. BSI, 2011.

18. British Standard Institution,BS 882: 1992. Specification for aggregates from natural sources for concrete. BSI, 1992.

19. British Standards Institution. BS. 12350-2:2009. Testing Fresh Concrete-Part 2: Slump Test. BSI. 2009.

20. British Standard Institution, BS. 4449:2005+A3:2016: Steel for the reinforcement of concrete. Weldable reinforcing steel. Bar, coil and decoiled product. Specification., BSI, 2005.

21. Etxeberria, M. E. Vázquez, A. Marí A and M. Barra. Influence of amount of recycled coarse aggregates and production process on properties of recycled aggregate concrete. Cement and concrete research, 2007. 37(5): p. 735-742.

22. Bravo. M, J. De Brito, J. Pontes and Evangelista L. Durability performance of concrete with recycled aggregates from construction and demolition waste plants. Construction and Building Materials, 2015. 15(77): p. 357-369.

23. Levy SM and P Helene. Durability of recycled aggregates concrete: a safe way to sustainable development. Cement and concrete research, 2004. 34(11): p.1975-1980.

24. Kearsley, E.P. and A. Joyce, Effect of corrosion products on bond strength and flexural behaviour of reinforced concrete slabs. Journal of the South African Institution of Civil Engineering, 2014. 56(2): p. 21-29.

25. Yalciner, H., O. Eren, and S. Sensoy, An experimental study on the bond strength between reinforcement bars and concrete as a function of concrete cover, strength and corrosion level. Cement and Concrete Research, 2012. 42(5): p. 643-655.

26. British Standards Institution. BS.12390-3:2009: Testing hardened concrete. Compressive strength of test specimens. BSI, 2009.

27. RILEM/CEB/FIP. Recommendations on reinforcement steel for reinforced concrete.1983. (RC 6, CEB News 73). 
28. American Society for Testing and Materials G1-03. 2011. Standard practice for preparing, cleaning, and evaluating corrosion test specimens. American Society for Testing and Materials ASTM, 2011.

29. Li, W., et al., Effects of nano-particles on failure process and microstructural properties of recycled aggregate concrete. Construction and Building Materials, 2017. 142: p. 42-50.

30. Rao, M.C., S. Bhattacharyya, and S. Barai, Influence of field recycled coarse aggregate on properties of concrete. Materials and Structures, 2011. 44(1): p. 205-220.

31. Behera $M$, et al. Recycled aggregate from $C \& D$ waste $\&$ its use in concrete-a breakthrough towards sustainability in construction sector: a review. Construct Build Mater 2014. (68):50116.

32. Fernandez, I., M. Etxeberria, and A.R. Marí, Ultimate bond strength assessment of uncorroded and corroded reinforced recycled aggregate concretes. Construction and Building Materials, 2016. 111: p. 543-555.

33. Coccia, S., S. Imperatore, and Z. Rinaldi, Influence of corrosion on the bond strength of steel rebars in concrete. Materials and structures, 2016. 49(1-2): p. 537-551.

34. Auyeung, Y., P. Balaguru, and L. Chung, Influence of Corrosion on Bond Behavior of Reinforcement Bars. Special Publication, 2000. 193: p. 1051-1074.

35. Cabrera, J., Deterioration of concrete due to reinforcement steel corrosion. Cement and concrete composites, 1996. 18(1): p. 47-59.

36. Wei-liang, J. and Z. Yu-xi, Effect of corrosion on bond behavior and bending strength of reinforced concrete beams. Journal of Zhejiang University-Science A, 2001. 2(3): p. 298-308.

37. Al-Sulaimani, G., M. Kaleemullah, and I. Basunbul, Influence of corrosion and cracking on bond behavior and strength of reinforced concrete members. Structural Journal, 1990. 87(2): p. 220-231.

38. Wassouf, M., Bond and ductility of concrete reinforced with various steel bars surface and ductility conditions. 2015, University of Birmingham.

39. $\mathrm{ACl}$ Committee 408. Bond development of straight reinforcing bars in tension (ACl 408R-03). Farmington Hills, USA: American Concrete Institute; 2003.

40. Metelli, G. and G.A. Plizzari, Influence of the relative rib area on bond behaviour. Magazine of Concrete Research, 2014. 66(6): p. 277-294.

41. Hamad, B.S. and M.S. Itani, Bond strength of reinforcement in high performance concrete: role of silica fume, casting position, and superplasticizer dosage. Materials Journal, 1998. 95(5): p. 499-511.

42. Shang, H.-s., et al., Bond behavior of steel bar embedded in recycled coarse aggregate concrete under lateral compression load. Construction and Building Materials, 2017. 150: p. 529-537.

43. Sonebi, M., R. Davidson, and D. Cleland. Bond between Reinforcement and Concrete-Influence of Steel Corrosion. in International conference on durability of building materials and components, Porto-Portugal. 2011.

44. Neville, A.M., Concrete: Neville's insights and issues. 2006: Thomas Telford.

45. CEB-FIB, M.C., First Draft. 2010, Volume.

46. Australian Standard, A., 3600. Concrete Structures, Standards Australia, Sydney, 2004.

47. Orangun, C., J. Jirsa, and J. Breen. A reevaulation of test data on development length and splices. in Journal Proceedings. 1977.

48. Darwin, D., et al. Development length criteria: bars not confined by transverse reinforcement. 1992. American Concrete Institute.

49. Esfahani, M.R. and B.V. Rangan, Bond between normal strength and high-strength concrete (HSC) and reinforcing bars in splices in beams. Structural Journal, 1998. 95(3): p. 272-280.

50. Lee, H.-S., T. Noguchi, and F. Tomosawa, Evaluation of the bond properties between concrete and reinforcement as a function of the degree of reinforcement corrosion. Cement and Concrete research, 2002. 32(8): 1313-1318. 
51. Chung, L., J.-H.J. Kim, and S.-T. Yi, Bond strength prediction for reinforced concrete members with highly corroded reinforcing bars. Cement and concrete composites, 2008. 30(7): p. 603611.

52. Bhargava, K., et al., Corrosion-induced bond strength degradation in reinforced concreteAnalytical and empirical models. Nuclear Engineering and Design, 2007. 237(11): p. 11401157.

53. Kivell, A., A. Palermo, and A. Scott. Corrosion related bond deterioration and seismic resistance of reinforced concrete structures. Structures, 2012.

54. Feng, Q, Visintin P, Oehlers DJ. Deterioration of bond-slip due to corrosion of steel reinforcement in reinforced concrete. Magazine of Concrete Research. 2015. 68(15):768-81.

55. Erdem, S. et al., Micromechanical damage analysis and engineering performance of concrete with colloidal nano-silica and demolished concrete aggregates. Construction and Building Materials, 2018. 171: p. 634-642.

56. Xiao, J. et al., An overview of study on recycled aggregate concrete in China (1996-2011). Construction and Building materials. 2012. 31: 364-383.

57. Guo, H. et al. Durability of recycled aggregate concrete-a review. Cement and Concrete Composites. 2018. 89: p. 251-259. 